Article

\title{
Investigating dynamic interdependencies between traditional and digital assets during the COVID-19 outbreak: Implications for G7 and Chinese financial investors
}

\author{
Ahmed Jeribi ${ }^{1 *}$, and Wafa Kammoun Masmoudi ${ }^{2}$ \\ 1 Faculty of Economics and Management of Mahdia, University of Monastir, Tunisia; ahmedjeribi07@yahoo.fr \\ 2 Institute of Higher Commercial Studies of Carthage, University of Carthage Tunisia; \\ wafa.kammoun.ihec@gmail.com \\ * Correspondence: ahmedjeribi07@yahoo.fr
}

Received: 9 June 2021; Accepted: 25 August 2021; Published: 30 August 2021

\begin{abstract}
This paper discusses the relationship between the volatilities of traditional and digital assets before and during the COVID-19 pandemic. Using daily data relevant to the period ranging from January 4, 2016, to April 15, 2020, the results of the DCC-MVGARCH model indicate that the stock markets responded to the Coronavirus outbreak as the crypto market with worrying volatility. Before this outbreak, Bitcoin and gold are considered as a hedge for US, English, French, German, and Italian financial investors. The conditional correlation between stock indices and other assets was skyrocketing during this pandemic, except for the couple SSE-Ripple.
\end{abstract}

Keywords: Cryptocurrencies, Gold, Stock Markets, Covid-19 Pandemic, G7, China

JEL codes: $\mathrm{C} 22 ; \mathrm{C} 5 ; \mathrm{G} 1$

\section{Introduction}

The template presents the sections that can be used in a manuscript. Each section has an As the COVID-19 virus outbreak news moves far beyond China, the Coronavirus is sending ripples through the stock market and world economy. In just the last few months, this pandemic has managed to plunder and destabilize the world's financial system. For centuries, during numerous crises, gold has traditionally been considered a haven. Since the Bretton Woods crash, gold does not have the same significance in the international monetary system. However, it attracts tremendous interest from investors, the media, and researchers. Due to the growing volatility of financial markets, the diversification of portfolios through hedges is becoming more relevant. During the global economic and financial crisis that started in 2007 with the subprime mortgage market crisis in the United States, gold prices rose dramatically, while other assets suffered losses (Beckmann et al, 2015). In recent years, correlations between most types of assets have increased dramatically. However, gold is still considered to be a zero-beta asset (McCown and Zimmerman, 2006) and is still assumed to be unrelated to other assets (Baur and Lucey, 2010). Bentes (2016) suggested that gold returns had changed from long-range pre-crisis dependency to short-term memory during the crisis period. It also appears that gold is used to act as a hedge in times of financial instability (Selmi et al. 2018; Bouri et al 2020; Jareno et al, 2020; Demir et al, 2020; Jeribi and Snene Manzli, 2021, Kumah et al, 2021; Jeribi and Ghorbel, 2021; Ghorbel and Jeribi, 2021, a,b,c).

Dyhberg (2016) asserted that the global uncertainty surrounding the 2007 global financial crisis has eased the emergence of the first decentralized blockchain-based cryptocurrency and strengthened 
its popularity. Bitcoin was designed by Nakamoto (2008). It facilitated electronic payments between individuals without going through third parties. Bitcoin has been the subject of challenges and opportunities for policymakers, entrepreneurs, consumers, and economists since its inception. Bitcoin is considered to be different from any other financial market asset. It creates new opportunities for stakeholders concerning portfolio analysis, risk management, and consumer sentiment analysis (Dyhberg, 2016). Bitcoin is compared to gold because it has many similarities. Neither of them is national or controlled by the government. They are being mined by several independent operators and companies. Gold has some inherent value but most likely does not justify its current market value (Dyhrberg, 2016).

According to Brière et al. (2015), Selmi et al. (2018), Symitsi and Chalvatzi (2019), and Baur and Hoang (2020), Bitcoin is defined as a highly volatile asset. It has become a major theme in the financial press and academia. Given the acceptance of Bitcoin as an investment tool and its increasing importance, the modeling of Bitcoin price volatility is becoming important for investment decisions and risk management (Katsiampa, 2017). Many studies have used GARCH-Family Models as the backbone of Bitcoin Volatility Modeling (Katsiampa, 2017, Bouri et al., 2017; Guesmi et al., 2019; Fakhfekh and Jeribi, 2020). Around the same period, another line of analysis focuses on the diversification ability of Bitcoin by researching the correlation between traditional asset classes and Bitcoin. Various studies apply a variety of methods and conclude that Bitcoin is very weakly correlated with conventional assets such as bonds, commodities, and equities (e.g., Bouri et al., 2017; Gajardo et al., 2018; Klein et al., 2018; Tiwari et al., 2019; Charfeddine et al., 2020; Jeribi and Fakhfekh, 2021; Ghorbel and Jeribi, 2021, a,b,c, Jeribi and Ghorbel, 2021). In addition, Brière et al. (2015), Bouri et al. (2017), Kajtazi and Moro (2018), Guesmi et al. (2019), Charfeddine et al. (2020), Lahiani et al (2021), and Jeribi et al. (2021), as well as Fakhfekh et al. (2021), suggested significant benefits for portfolio diversification and risk management when Bitcoin was added.

Many of the works that analyzed volatility dynamics, correlations, and hedge ratios between cryptocurrencies and other assets used multivariate GARCH models such as BEKK (Klein et al.2018; Ghorbel and Jeribi, 2021, a,b,c, Jeribi and Ghorbel, 2021 ), DCC (Bouri et al., 2017; Ghorbel and Jeribi, 2021, a,b,c; Jeribi and Ghorbel, 2021) or ADCC (Gajardo et al., 2018; Tiwari et al., 2019; Fakhfekh et al., 2021). However, the estimation of GARCH models on big data sets faces difficulties. E.g., the BEKK and VARMA-GARCH models have a low likelihood function due to the existence of a large number of free parameters, rendering estimation difficult for models of more than two variables. Conditional correlation models such as Constant Conditional Correlation (CCC), Dynamic Conditional Correlation (DCC), or Asymmetric DCC (ADCC) are more robust to these estimation problems and require more variables to be integrated into the model. Conditional correlation models are structured to fix some of the issues found with the BEKK and VECH models. They are simple to approximate, yet have computational power with large data sets and are commonly used in the calculation of hedge ratios.

Most of the works analyze returns and treat volatility for Bitcoin as a cryptocurrency market's leader. Many new cryptocurrencies appear and most of them are developed further based on blockchains. However, most of the literature focuses only on Bitcoin. Corbet et al. (2018) analyzed the relationships between three cryptocurrencies (Bitcoin, Ripple, and Litecoin) and a variety of other financial assets. Their results as those of Corbet et al. (2019) reveal that cryptocurrencies are rather isolated from the other markets. The values for directional return and volatility from Bond, Gold, VIX, FX, GSCI, and S\&P 500 to cryptocurrency markets are very low. Thereby, they suggest a role for cryptocurrencies as diversifier assets for investors with short investment horizons. Using a generalized DCC class model, Aslanidis et al (2019) investigate the actions of conditional associations between four cryptocurrencies (Bitcoin, Monero, Dash, and Ripple), S\&P 500, bond, and gold. These researchers claim that the cryptocurrencies analyzed are strongly correlated and that the associations between cryptocurrencies and conventional financial assets are negligible. Using a copula-ADCC-EGARCH model, Tiwari et al. (2019) research time-differentiated correlations between the S\&P 500 and six other cryptocurrencies. They find very small time-varying associations. Charfeddine et al. (2020) 
investigated the economic and financial benefits of Bitcoin and Ethereum, for financial investors by studying their capabilities to generate benefits from portfolio diversification and hedging strategies. By estimating static and time-varying tail copulas, they found evidence of time-varying dependence and the absence of asymmetric tail dependence between digital and conventional financial assets. They suggested that digital assets can offer new opportunities for portfolio diversification by including only a small weight of cryptocurrencies in a portfolio of traditional financial assets. Jareno et al. (2020) analyzed the sensitivity of Bitcoin returns to changes in gold price returns, US stock market returns, interest rates, oil prices, and the VIX index. The results indicated that Bitcoin is negatively influenced by VIX, nominal interest rates, and crude oil prices. However, the relations between Bitcoin and gold price returns are positive. Bitcoin is considered a safe-haven asset during economic turmoil. Bouri et al. (2020) compared the safe-haven properties of Bitcoin, gold, and the commodity index against developed, emerging, USA, and Chinese stock market indices. They show that the interdependence between Bitcoin, gold, commodities, and the stock markets is not very strong. They concluded that Bitcoin can be seen as a new virtual gold. It has some of the virtuousness of gold against the extreme drop in the stock market indices.

Bitcoin was created out of the 2008 financial crisis. The Coronavirus pandemic is looking more and more like its first real test in a crisis scenario, as well as the other digital assets. Using the multivariate DCC-GARCH model, we explore the time-varying conditional correlations between stock markets (G7 and China) on the one hand and cryptocurrencies and gold on the other hand. We tested the haven property of cryptocurrencies and Gold from January 4, 2016, to April 15, 2020. The layout of this paper is as follows. Section 2 gives an outline of the econometric methodology adopted. Section 3 is devoted to highlighting the relevant data and empirical findings. Finally, Section 4 concludes.

\section{Empirical Methodology}

To determine the nature of the relation between Cryptocurrencies and financial indices of G7 and China, we use the Multivariate GARCH analysis. The use of GARCH models is justified by the presence of heteroscedasticity of the error terms. It is well known that GARCH models offer more dynamic volatility than other models that represent constant variance. Besides, the multivariate GARCH model can present dynamic conditional mean and conditional covariance opposite to the univariate GARCH model. Since the cryptocurrency market is found to be sensitive to related events such as bankruptcy of an exchange or change in regulations, we are using MVGARCH to detect any return volatility within our studied markets. Among all the GARCH models, we are using the DCCMVGARCH introduced by Engle in 2002. It has been shown in the literature that this model is the most adequate to analyze the cryptocurrency market. It also requires fewer parameters comparing to other GARCH models. Moreover, this upgraded version of GARCH allows more flexibility and is characterized by random walks in returns obtained by pre-filtering and a variance-covariance structure of past returns events. Thus, Structural interdependencies in return-risk are captured by the dynamic behavior of the conditional covariance matrix.

Hence, the first conditional moments (means) of indices returns through a VAR process is presented as follow:

$$
\begin{aligned}
& R_{S, t}=c_{i}+\sum_{i=1}^{p_{S}} a_{S i} R_{S t-i}+\sum_{i=1}^{p_{B}} a_{B i} R_{B t-i}+\varepsilon_{S t} \\
& R_{B, t}=c_{i}+\sum_{i=1}^{p_{B}} a_{B i} R_{B t-i}+\sum_{i=1}^{p_{S}} a_{B i} R_{B t-i}+\varepsilon_{B t}
\end{aligned}
$$

Where $c_{i}$ is a constant, $\mathrm{RS}, \mathrm{t}$, and $\mathrm{RB}, \mathrm{t}$ is the crypto/Gold and stock market conditional mean returns, respectively. These returns are functions of their past market returns, those of the other assets, and their past idiosyncratic shocks. pB and pS are the numbers of autoregressive terms. The choice of VAR order is made based on the parameters significance and Bayesian information criterion (BIC). The residual vector $\varepsilon_{t}$ is identically distributed according to a student-t distribution.

The structural equation of the MV-GARCH model is as follow: 


$$
\sigma_{\mathrm{i}, \mathrm{t}}^{2}=\omega_{\mathrm{i}}+\alpha_{\mathrm{i}} \varepsilon_{\mathrm{t}-1}^{2}+\beta_{i} \sigma_{, \mathrm{t}-1}^{2}+\sum_{i=1}^{2} \gamma_{i t} D_{i t}
$$

Where $\sigma_{\mathrm{t}}^{2}$ is the conditional variance, $\alpha_{\mathrm{i}}$ and $\beta_{\mathrm{i}}$ represent return volatilities from shocks in own returns reflected respectively by the ARCH and GARCH parameters while $\omega_{i}$ is a constant. The return volatilities are calculated based on the sum of ARCH and GARCH terms $\left(\alpha_{i}+\beta_{i}\right)$ which measures the persistence of volatility during the studied period and must be less than one for systematic volatility to stabilize. $\gamma_{i t}$ represents coefficients of dummy variables which are included in conditional variance equation to determine volatility estimates relating directly to the COVID-19 pandemic.

\section{Data and Results}

The empirical study research involves 1002 daily observations of five cryptocurrencies, Gold, G7, and Chinese market indices, sampled from 4 January 2016 to 15 April 2020. Daily time series data are collected for stock prices of the United States (S\&P500), France (CAC40), Germany (DAX30), the United Kingdom (FTSE 100), Italy (MIB 30), Japan (Nikkei 225), Canada (SP-TSX), and China (SSE) from DataStream. From the same database, we extracted the gold prices. Data concerning the five studied cryptocurrencies (Bitcoin, Dash, Ethereum, Ripple, and Monero) was collected from the Coin Market Cap basis. Daily returns are defined by $r_{t}=100 * \ln \left(p_{t} / p_{t-1}\right)$, with $P_{i, t}$ denoting indices i closing price at time $t$. This transformation of data is usually employed for index series to obtain stationary data. In addition, figures 1 and 2 confirm that the return series are stationary.

Besides, we use two dummy vectors to assign two sub-periods of equal length. D1, $t$ shows crisis dummy preceding the stock market influence of the COVID-19 outbreak taking the value of 1 if $t$ falls in the specific period and 0 otherwise. Likewise, D2, $\mathrm{t}$ signifies a crisis dummy for the succeeding period. This specification is helpful since the benchmark period for the comparison of the stockCryptocurrency versus Gold association before an onset crisis is not based on the entire sample. Rather, the comparison is based on pre and post-crisis periods of the same time frame, which is expected to reveal the changes in investor's behavior (Baur and Lucey, 2009).

To construct a tractable econometric model, we consider the COVID-19 affected period from January 01 to April 15, 2020, enveloping 73 observations. Further, to examine whether the Crypto versus Bond-stock market relationship for the immediately preceding period was similar or not, we consider the trading days of equal length. Furthermore, to control the relationship, we consider an additional 955 preceding trading days.

Table 1. Descriptive statistics

\begin{tabular}{ccccccccc}
\hline Assets & Mean & Min & Max & Std Dev & Skewness & Kurtosis & J-B & ARCH test \\
\hline Traditional assets & & & & & & & & \\
SP500 & 0,030 & $-12,765$ & 8,968 & 1,195 & $-1,168^{* * *}$ & $26,692^{* * *}$ & $32934,262^{* * *}$ & $148,086^{* * *}$ \\
FTSE & $-0,007$ & $-11,512$ & 8,667 & 1,036 & $-1,503^{* * *}$ & $23,042^{* * *}$ & $24772,004^{* * *}$ & $44,781^{* * *}$ \\
Nikkei & 0,005 & $-8,253$ & 7,731 & 1,269 & $-0,216^{* *}$ & $7,525^{* * *}$ & $2606,501^{* * *}$ & $24,468^{* * *}$ \\
DAX 30 & 0,001 & $-13,055$ & 10,414 & 1,209 & $-1,350^{* * *}$ & $21,256^{* * *}$ & $21061,562^{* * *}$ & $29,677^{* * *}$ \\
CAC 40 & $-0,003$ & $-13,098$ & 8,056 & 1,197 & $-1,937^{* * *}$ & $21,388^{* * *}$ & $21673,720^{* * *}$ & $45,039^{* * *}$ \\
FTSE MIB & $-0,019$ & $-18,541$ & 8,549 & 1,529 & $-2,552^{* * *}$ & $29,223^{* * *}$ & $40371,536^{* * *}$ & $19,623^{* * *}$ \\
S\&P/TSX & 0,007 & $-13,176$ & 11,294 & 1,083 & $-2,298^{* * *}$ & $55,456^{* * *}$ & $142048,828^{* * *}$ & $86,310^{* * *}$ \\
SSE & $-0,015$ & $-7,994$ & 1,324 & 1,151 & $-0,899^{* * *}$ & $7,975^{* * *}$ & $3066,182^{* * *}$ & $10,608^{* * *}$ \\
GOLD & 0,044 & $-4,153$ & 4,297 & 0,821 & $0,149^{* *}$ & $3,446^{* * *}$ & $548,680^{* * *}$ & $17,055^{* * *}$ \\
Digital assets & & & & & & & & \\
Bitcoin & 0,249 & $-49,728$ & 22,175 & 4,844 & $-1,030^{* * *}$ & $13,104^{* * *}$ & $8072,474^{* * *}$ & $3,337^{* * *}$ \\
Dash & 0,283 & $-51,594$ & 56,488 & 7,413 & 0,078 & $9,407^{* * *}$ & $4061,051^{* * *}$ & $6,262^{* * *}$ \\
Ethereum & 0,467 & $-57,987$ & 49,758 & 7,539 & $0,235^{* * *}$ & $7,777^{* * *}$ & $2784,848^{* * *}$ & $6,720^{* * *}$ \\
Monero & 0,417 & $-51,954$ & 75,051 & 8,369 & $1,271^{* * *}$ & $13,447^{* * *}$ & $8591,873^{* * *}$ & $37,029^{* * *}$ \\
Ripple & 0,319 & $-56,334$ & 74,069 & 8,139 & $1,765^{* * *}$ & $16,115^{* * *}$ & $12484,749^{* * *}$ & $15,292^{* * * *}$ \\
\hline
\end{tabular}

Note: ${ }^{* * *},{ }^{* *},{ }^{*}$ indicate the estimators' significance at the $1 \%, 5 \%$ and $10 \%$ levels, respectively 
Table 1 presents a summary of statistics of conventional and digital assets' returns. Worth highlighting, the conventional assets returns are lower than those of cryptocurrencies. All assets recorded mean positive returns except the stock market indices of Italy, France, and China. Whereas, for the conventional assets, gold presents the lowest risk. In addition, Bitcoin is the least risky cryptocurrency. More specifically, Ethereum and Monero have the highest average return and standard deviation, which suggests that the higher expected profits are partially balanced by higher volatility. Concerning the normality test, Jarques Bera shows that our variables have very high values which indicates that our data is not normally distributed. This confirms the values of Kurtosis and skewness. Note that negative skewness values are present for all stock indices and Bitcoin. Bitcoin and Monero have the highest excess kurtosis among the cryptocurrencies. The empirical statistics of the Engle (1982) test for conditional heteroscedasticity are significant for all cases suggesting the presence of ARCH effects in returns which justifying our choice of GARCH models.

Figure 1. Conditional Volatility of Cryptocurrencies and Gold.
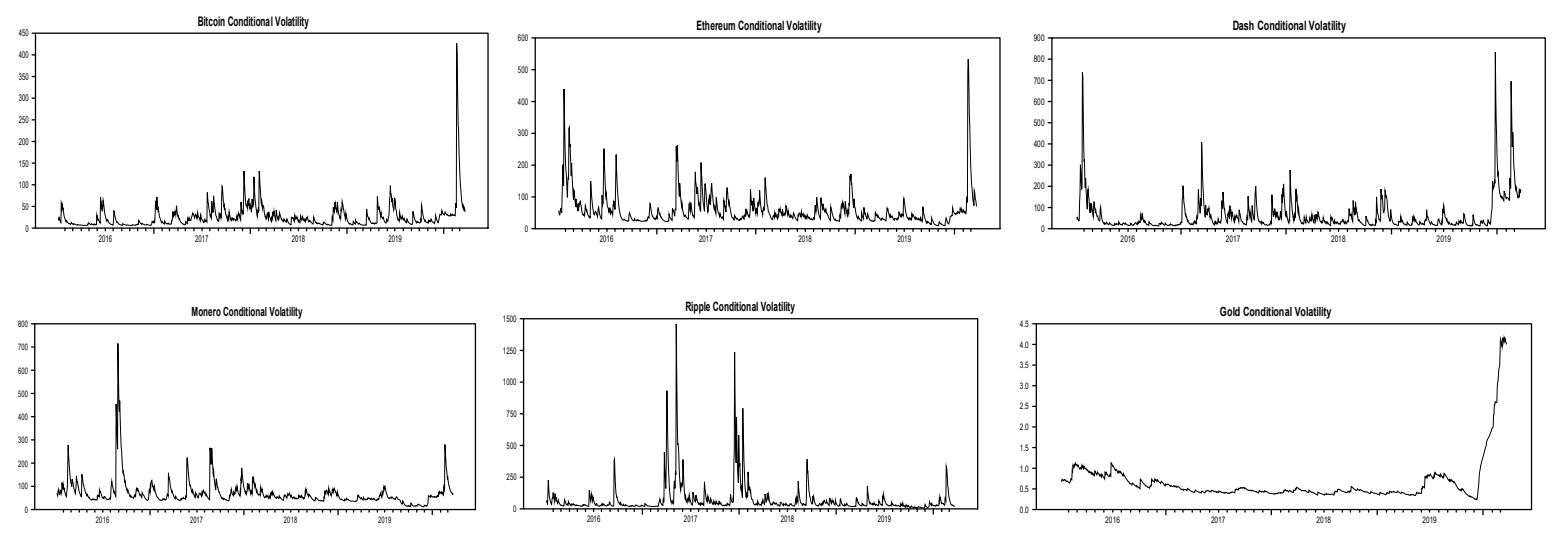

Figure 2. Conditional volatilities of G7 and Chinese stock market indices
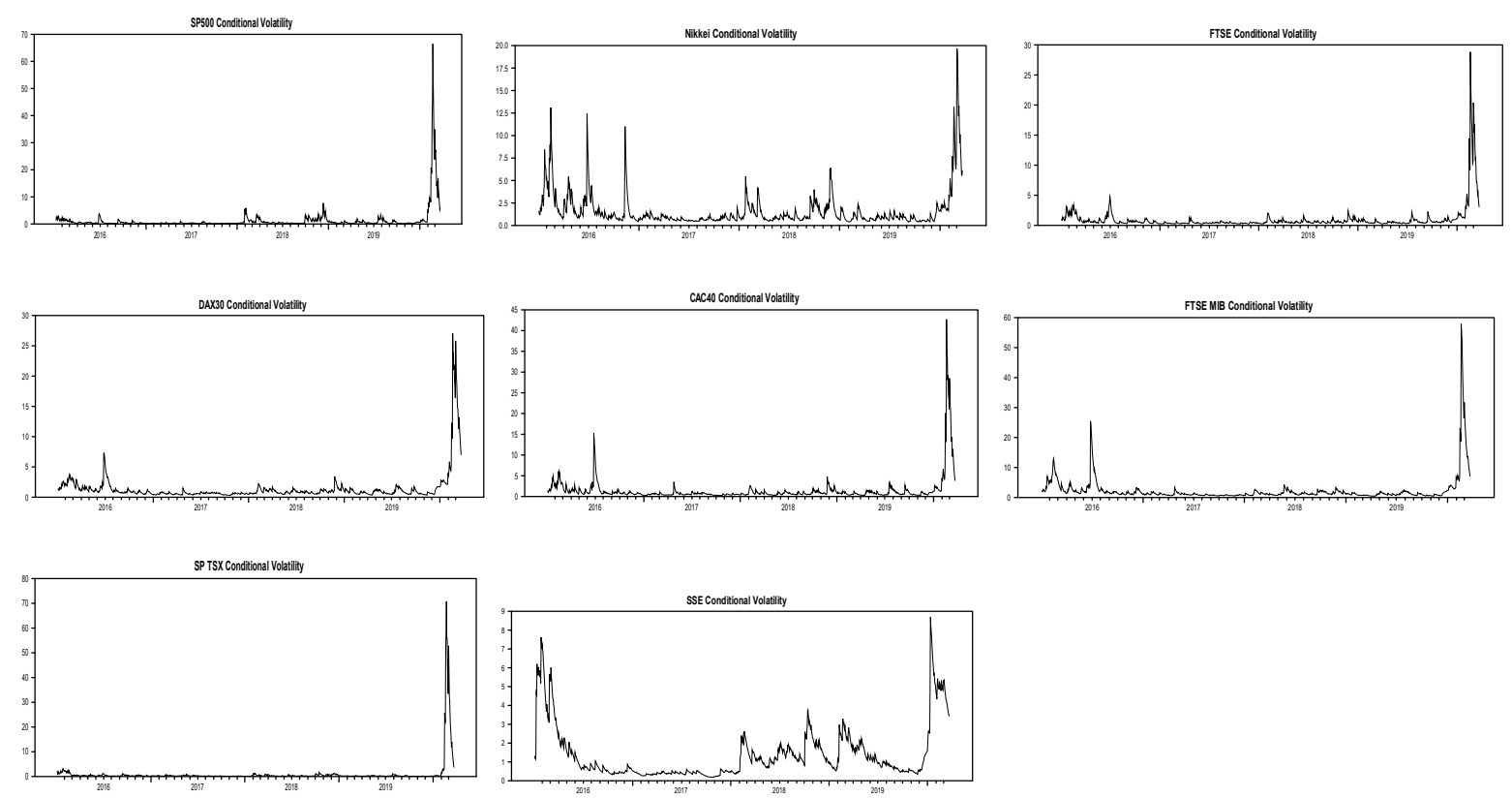
From Figure 1, we confirm this finding and can observe that the returns of digital assets are more volatile than the returns of the indices (Figure 2), which means that Cryptocurrencies can be defined as highly volatile assets. This result is aligned with Brière et al. (2015), Selmi et al. (2018), Beniki et al. (2019), Symitsi and Chalvatzi (2019), and Baur and Hoang (2020). In addition, Ripple and Monero are among the most volatile; however, Bitcoin is the least volatile of all. We identify high volatility for all cryptocurrencies at the end of 2017, particularly with the launch of Bitcoin futures. This high volatility continued until early 2018, coinciding with the corrections of speculative bubbles that caused an increase in cryptocurrency prices. The crypto market became more volatile after the appearance of the COVID-19 in early 2020. With China and South Korea accounting for more than 70\% of Bitcoin's mining capacity, we note that the massive effect was reported as the virus began to spread to Asian countries, much less to the world. It can be shown that digital assets present almost identical movements of volatility. The stock markets responded to the Coronavirus outbreak as a crypto market with worrying volatility, as traders were panic sold out of fear. Indeed, equities have plummeted and stock market volatility has skyrocketed. Moreover, the oil price battle between Russia and Saudi Arabia, and the low price of oil remain the stock markets more volatile. Gold is considered a haven (Baur and Lucey, 2010; Klein et al, 2018; Charfeddine et al, 2020; Ghorbel and Jeribi; 2021, a, b,c, Jeribi and Ghorbel 2021; Lahiani et al, 2021; Fakhfekh et al 2021, Jeribi et al, 2021) and investment in times of crisis. Gold is generally less volatile than other commodities, but it was volatile this time. The price of gold continued to rise by mid-February, guided by two main factors. The first was a safe-haven investment resulting from global uncertainty and the second was low to negative returns on highquality government bonds. In mid-March, the price of gold plummeted along with most other commodities and markets. Gold is not playing the role of a haven that it has performed in the past.

The DCC model is the preferred model for most of the models tested. However, except for interdependencies between FTSE / CAC40 and Monero / Ripple; Nikkei and Monero/Gold; DAX30 and Ripple; S\&P TSX and Dash/Monero. Note that the restricted correlation model (Constant Conditional Correlation) shows less evidence of volatility spillovers. First, the estimated coefficients of DCC(A) and DCC(B) are both positive and statistically significant in all cases. These estimated coefficients sum to a value that is less than one. This implies that the dynamic conditional correlation is mean reverting in all cases. For the CCC model, the correlation coefficients are each positive and statistically significant at the $1 \%$ or $5 \%$ level. The highest correlation is between Dash and S\&P TSX and the second-highest correlation is between Monero and S\&P TSX. The results of the mean equations indicate that the S\&P 500 with a lag of one period affects the current value of the cryptocurrency market. However, The S\&P 500 with a lag of two periods is not statistically significant for all cases. On the other hand, only the lagged Bitcoin with a lag of one period can affect the current values of the S\&P 500. Indeed, the coefficient is statistically significant at the $10 \%$ level. Besides, gold with a two lag is statistically significant and affects the S\&P 500. For S\&P TSX with a lag of one period, the influence is shown only with Bitcoin, Ethereum, and Ripple.

In the next step, the two-dimensions asymmetric DCC-GARCH $(1,1)$ model is estimated, and the estimation results are shown in the second part of Table 2. $\alpha_{i}$ are conditional ARCH effects that measure the short-term persistence, while $\beta_{i}$ is conditional GARCH effects that measure the long-term persistence. We mainly focus on the GARCH effect caused by heteroscedasticity. For the entire sample, the own conditional ARCH effects $\alpha_{i}$ are significant at the $1 \%$ level, which means that each market is influenced by the short shocks of their own. Meanwhile, the own conditional GARCH effects $\beta_{i}$ are also significant at the $1 \%$ level. Each market is influenced by the volatility of its market. For each market, the estimated $\alpha_{i}$ values are smaller than their respective estimated $\beta_{i}$ values, indicating that their volatility long-run (GARCH) persistence is larger than short-run $(\mathrm{ARCH})$ persistence.

The stationarity and stability conditions of this model were also satisfied as the sum of ARCH and GARCH terms were less than unity $\left(\alpha_{i}+\beta_{i}<1\right)$. 
Table 2. MV-DCC GARCH between Cryptocurrencies/Gold and SP500

\begin{tabular}{|c|c|c|c|c|c|c|}
\hline & Bitcoin & Dash & Ethereum & Monero & Ripple & Gold \\
\hline \multicolumn{7}{|l|}{ Mean Model (Xi) } \\
\hline \multirow[t]{2}{*}{$\mathrm{Xi}(1)$} & 0,026 & 0,010 & $0,077^{* *}$ & $-0,047$ & $-0,041$ & $-0,005$ \\
\hline & $(0,489)$ & $(0,780)$ & $(0,013)$ & $(0,145)$ & $(0,200)$ & $(0,874)$ \\
\hline \multirow[t]{2}{*}{$\mathrm{Xi}(2)$} & 0,026 & $0,073^{* *}$ & 0,015 & 0,021 & $-0,010$ & $0,052^{*}$ \\
\hline & $(0,443)$ & $(0,016)$ & $(0,636)$ & $(0,521)$ & $(0,767)$ & $(0,076)$ \\
\hline \multirow{2}{*}{ SP500(1) } & $0,288^{*}$ & $0,338^{*}$ & $0,543^{* *}$ & $0,588^{* * *}$ & $0,861^{* * *}$ & 0,035 \\
\hline & $(0,067)$ & $(0,085)$ & $(0,014)$ & $(0,006)$ & $(0,000)$ & $(0,117)$ \\
\hline \multirow[t]{2}{*}{ SP500(2) } & 0,080 & 0,182 & 0,009 & $-0,199$ & $-0,378^{* *}$ & $-0,011$ \\
\hline & $(0,594)$ & $(0,374)$ & $(0,966)$ & $(0,355)$ & $(0,013)$ & $(0,652)$ \\
\hline \multirow[t]{2}{*}{ Constant } & 0,176 & $-0,054$ & 0,102 & 0,152 & $-0,317^{* *}$ & 0,024 \\
\hline & $(0,169)$ & $(0,759)$ & $(0,616)$ & $(0,514)$ & $(0,069)$ & $(0,313)$ \\
\hline \multicolumn{7}{|c|}{ Mean Model(SP500) } \\
\hline \multirow[t]{2}{*}{$\mathrm{Xi}(1)$} & $0,006^{*}$ & 0,002 & 0,004 & $-0,002$ & 0,000 & 0,024 \\
\hline & $(0,083)$ & $(0,432)$ & $(0,148)$ & $(0,361)$ & $(0,809)$ & $(0,297)$ \\
\hline \multirow[t]{2}{*}{$\mathrm{Xi}(2)$} & 0,000 & $-0,003$ & 0,000 & 0,000 & $-0,002$ & $-0,042$ \\
\hline & $(0,952)$ & $(0,248)$ & $(0,991)$ & $(0,868)$ & $(0,360)$ & $(0,086)$ \\
\hline \multirow[t]{2}{*}{ SP500(1) } & $-0,075^{* *}$ & $-0,076^{* *}$ & $-0,075^{* *}$ & $-0,080^{* * *}$ & $-0,076^{* * *}$ & $-0,074^{* *}$ \\
\hline & $(0,019)$ & $(0,032)$ & $(0,021)$ & $(0,007)$ & $(0,011)$ & $(0,018)$ \\
\hline \multirow[t]{2}{*}{ SP500(2) } & 0,023 & 0,023 & 0,013 & 0,019 & 0,017 & $-0,001$ \\
\hline & $(0,457)$ & $(0,510)$ & $(0,704)$ & $(0,531)$ & $(0,570)$ & $(0,978)$ \\
\hline \multirow[t]{2}{*}{ Constant } & $0,092^{* * *}$ & $0,091^{* * *}$ & $0,094^{* * *}$ & $0,094^{* * *}$ & $0,098^{* * *}$ & $0,098^{* * *}$ \\
\hline & $(0,000)$ & $(0,000)$ & $(0,000)$ & $(0,000)$ & $(0,000)$ & $(0,000)$ \\
\hline \multirow[t]{2}{*}{$\omega_{1}$} & $1,195^{* * *}$ & $3,109^{* * *}$ & $4,332^{* * *}$ & $5,173^{* * *}$ & $4,940^{* * *}$ & $0,006^{* * *}$ \\
\hline & $(0,000)$ & $(0,000)$ & $(0,002)$ & $(0,001)$ & $(0,000)$ & $(0,073)$ \\
\hline \multirow[t]{2}{*}{$\omega_{2}$} & $0,038^{* * *}$ & $0,039^{* * *}$ & $0,038^{* * *}$ & $0,039^{* * *}$ & $0,040^{* * *}$ & $0,041^{* * *}$ \\
\hline & $(0,000)$ & $(0,000)$ & $(0,000)$ & $(0,000)$ & $(0,000)$ & $(0,000)$ \\
\hline \multirow[t]{2}{*}{$\alpha_{1}$} & $0,161^{* * *}$ & $0,209^{* * *}$ & $0,139^{* * *}$ & $0,087^{* * *}$ & $0,225^{* * *}$ & $0,023^{* * *}$ \\
\hline & $(0,000)$ & $(0,000)$ & $(0,000)$ & $(0,000)$ & $(0,000)$ & $(0,003)$ \\
\hline \multirow[t]{2}{*}{$\alpha_{2}$} & $0,228^{* * *}$ & $0,228^{* * *}$ & $0,230^{* * *}$ & $0,231^{* * *}$ & $0,234^{* * *}$ & $0,230^{* * *}$ \\
\hline & $(0,000)$ & $(0,000)$ & $(0,000)$ & $(0,000)$ & $(0,000)$ & $(0,000)$ \\
\hline \multirow[t]{2}{*}{$\beta_{1}$} & $0,798^{* * *}$ & $0,747^{* * *}$ & $0,792^{* * *}$ & $0,843^{* * *}$ & $0,723^{* * *}$ & $0,967^{* * *}$ \\
\hline & $(0,000)$ & $(0,000)$ & $(0,000)$ & $(0,000)$ & $(0,000)$ & $(0,000)$ \\
\hline \multirow[t]{2}{*}{$\beta_{2}$} & $0,732^{* * *}$ & $0,729^{* * *}$ & $0,729^{* * *}$ & $0,726^{* * *}$ & $0,723^{* * *}$ & $0,723^{* * *}$ \\
\hline & $(0,000)$ & $(0,000)$ & $(0,000)$ & $(0,000)$ & $(0,000)$ & $(0,000)$ \\
\hline \multirow[t]{2}{*}{$\gamma_{11}$} & 0,365 & $-0,516$ & $-2,740^{* *}$ & $-3,877^{* * *}$ & $-3,435^{* * *}$ & $-0,007^{* * *}$ \\
\hline & $(0,494)$ & $(0,594)$ & $(0,015)$ & $(0,003)$ & $(0,000)$ & $(0,023)$ \\
\hline \multirow{2}{*}{$\gamma_{12}$} & $-0,013$ & $-0,016$ & $-0,015$ & $-0,015$ & $-0,016^{*}$ & $-0,017$ \\
\hline & $(0,169)$ & $(0,122)$ & $(0,136)$ & $(0,123)$ & $(0,091)$ & $(0,127)$ \\
\hline \multirow[t]{2}{*}{$\gamma_{21}$} & $3,867^{* * *}$ & $16,065^{* * *}$ & 3,607 & 2,010 & $-0,728$ & $0,069^{* * *}$ \\
\hline & $(0,007)$ & $(0,010)$ & $(0,150)$ & $(0,349)$ & $(0,679)$ & $(0,002)$ \\
\hline \multirow[t]{2}{*}{$\gamma_{22}$} & $0,104^{*}$ & $0,111^{*}$ & $0,108^{*}$ & $0,105^{*}$ & $0,110^{* *}$ & $0,121^{*}$ \\
\hline & $(0,055)$ & $(0,058)$ & $(0,075)$ & $(0,100)$ & $(0,044)$ & $(0,062)$ \\
\hline $\operatorname{DCC}(\mathrm{A})$ & $0,013^{* * *}$ & $0,005^{*}$ & $0,034^{*}$ & $0,008^{* *}$ & $0,105^{* *}$ & $0,044^{* * *}$ \\
\hline & $(0,007)$ & $(0,087)$ & $(0,066)$ & $(0,049)$ & $(0,024)$ & $(0,001)$ \\
\hline $\mathrm{DCC}(\mathrm{B})$ & $0,986^{* * *}$ & $0,993^{* * *}$ & $0,915^{* * *}$ & $0,992^{* * *}$ & $0,654^{* * *}$ & $0,944^{* * *}$ \\
\hline & $(0,000)$ & $(0,000)$ & $(0,000)$ & $(0,000)$ & $(0,000)$ & $(0,000)$ \\
\hline Log Likelihood & $-4398,846$ & $-4821,018$ & $-4890,918$ & $-5020,119$ & $-4854,378$ & $-2443,858$ \\
\hline
\end{tabular}

Note: Where $\alpha_{\mathrm{i}}$ and $\beta_{\mathrm{i}}$ represent return volatilities from shocks in own returns reflected respectively by the ARCH and GARCH parameters while $\omega_{\mathrm{i}}$ is a constant. $\gamma_{\mathrm{ij}}$ measures the coefficients of dummy variables. ${ }^{*} * * * * *$ denote significance at the $1 \%, 5 \%$, and $10 \%$ level, respectively. P-Values are shown in brackets. Xi corresponds to the effect of past Crypto/Gold market performance, SP500 (i) corresponds to the effect of past index performance 
Table 3. MV-DCC GARCH (MV-CC GARCH) between Cryptocurrencies/Gold and FTSE

\begin{tabular}{|c|c|c|c|c|c|c|}
\hline & Bitcoin & Dash & Ethereum & Gold & Monero & Ripple \\
\hline \multicolumn{7}{|l|}{ Mean Model (Xi) } \\
\hline \multirow[t]{2}{*}{ Constant } & $0,245^{* *}$ & $-0,026$ & 0,148 & 0,031 & 0,175 & $-0,231$ \\
\hline & $(0,027)$ & $(0,889)$ & $(0,425)$ & $(0,160)$ & $(0,450)$ & $(0,183)$ \\
\hline \multicolumn{7}{|l|}{ Mean Model(FTSE) } \\
\hline \multirow[t]{2}{*}{ Constant } & 0,030 & 0,030 & $0,032^{*}$ & 0,033 & 0,030 & 0,029 \\
\hline & $(0,133)$ & $(0,129)$ & $(0,102)$ & $(0,113)$ & $(0,154)$ & $(0,169)$ \\
\hline \multirow[t]{2}{*}{$\omega_{1}$} & $1,235^{* * *}$ & $3,203^{* * *}$ & $4,565^{* * *}$ & $0,005^{*}$ & $4,944^{* * *}$ & $3,815^{* * *}$ \\
\hline & $(0,000)$ & $(0,000)$ & $(0,005)$ & $(0,110)$ & $(0,000)$ & $(0,000)$ \\
\hline \multirow[t]{2}{*}{$\omega_{2}$} & $0,049^{* * *}$ & $0,054^{* * *}$ & $0,052^{* * *}$ & $0,054^{* * *}$ & $0,053^{* * *}$ & $0,053^{* * *}$ \\
\hline & $(0,000)$ & $(0,000)$ & $(0,000)$ & $(0,000)$ & $(0,000)$ & $(0,000)$ \\
\hline \multirow[t]{2}{*}{$\alpha_{1}$} & $0,169^{* * *}$ & $0,213^{* * *}$ & $0,140^{* * *}$ & $0,021^{* * *}$ & $0,086^{* * *}$ & $0,142^{* * *}$ \\
\hline & $(0,000)$ & $(0,000)$ & $(0,000)$ & $(0,003)$ & $(0,000)$ & $(0,000)$ \\
\hline \multirow[t]{2}{*}{$\alpha_{2}$} & $0,162^{* * *}$ & $0,169^{* * *}$ & $0,163^{* * *}$ & $0,163^{* * *}$ & $0,166^{* * *}$ & $0,167^{* * *}$ \\
\hline & $(0,000)$ & $(0,000)$ & $(0,000)$ & $(0,000)$ & $(0,000)$ & $(0,000)$ \\
\hline \multirow[t]{2}{*}{$\beta_{1}$} & $0,793^{* * *}$ & $0,745^{* * *}$ & $0,786^{* * *}$ & $0,969^{* * *}$ & $0,848^{* * *}$ & $0,801^{* * *}$ \\
\hline & $(0,000)$ & $(0,000)$ & $(0,000)$ & $(0,000)$ & $(0,000)$ & $(0,000)$ \\
\hline \multirow[t]{2}{*}{$\beta_{2}$} & $0,767^{* * *}$ & $0,751^{* * *}$ & $0,757^{* * *}$ & $0,755^{* * *}$ & $0,754^{* * *}$ & $0,754^{* * *}$ \\
\hline & $(0,000)$ & $(0,000)$ & $(0,000)$ & $(0,000)$ & $(0,000)$ & $(0,000)$ \\
\hline \multirow[t]{2}{*}{$\gamma_{11}$} & 0,254 & $-0,527$ & $-2,871^{* *}$ & $-0,006^{* *}$ & $-3,675^{* * *}$ & $-2,772^{* * *}$ \\
\hline & $(0,601)$ & $(0,552)$ & $(0,024)$ & $(0,032)$ & $(0,001)$ & $(0,000)$ \\
\hline \multirow{2}{*}{$\gamma_{12}$} & 0,026 & 0,029 & 0,028 & 0,024 & 0,028 & 0,029 \\
\hline & $(0,285)$ & $(0,289)$ & $(0,240)$ & $(0,312)$ & $(0,215)$ & $(0,231)$ \\
\hline \multirow[t]{2}{*}{$\gamma_{21}$} & $3,543^{* * *}$ & $15,911^{* * *}$ & $5,087^{*}$ & $0,069^{* * *}$ & $2,807^{*}$ & 2,272 \\
\hline & $(0,008)$ & $(0,003)$ & $(0,066)$ & $(0,001)$ & $(0,104)$ & $(0,225)$ \\
\hline \multirow[t]{2}{*}{$\gamma_{22}$} & $0,167^{* *}$ & $0,174^{*}$ & $0,172^{* *}$ & $0,178^{*}$ & $0,174^{* *}$ & $0,174^{* *}$ \\
\hline & $(0,050)$ & $(0,067)$ & $(0,048)$ & $(0,075)$ & $(0,039)$ & $(0,045)$ \\
\hline \multirow[t]{2}{*}{$\mathrm{DCC}(\mathrm{A})$} & $0,011^{* *}$ & $0,057^{*}$ & $0,043^{* *}$ & $0,012^{*}$ & & \\
\hline & $(0,040)$ & $(0,093)$ & $(0,028)$ & $(0,073)$ & & \\
\hline \multirow[t]{2}{*}{$\mathrm{DCC}(\mathrm{B})$} & $0,987^{* * *}$ & $0,547^{* * *}$ & $0,788^{* * *}$ & $0,981^{* * *}$ & & \\
\hline & $(0,000)$ & $(0,003)$ & $(0,000)$ & $(0,000)$ & & \\
\hline \multirow[t]{2}{*}{$\mathrm{R}(2,1)$} & & & & & $0,060^{* *}$ & $0,101^{* * *}$ \\
\hline & & & & & $(0,017)$ & $(0,000)$ \\
\hline Log Likelihood & $-4495,923$ & $-4923,188$ & $-4986,435$ & $-2553,381$ & $-5119,294$ & $-4954,608$ \\
\hline
\end{tabular}

Note: Where $\alpha_{\mathrm{i}}$ and $\beta_{\mathrm{i}}$ represent return volatilities from shocks in own returns reflected respectively by the ARCH and GARCH parameters while $\omega_{\mathrm{i}}$ is a constant. $\gamma_{\mathrm{it}}$ represents coefficients of dummy variables. ${ }^{* * *}{ }^{* * *}$ denote significance at the $1 \%, 5 \%$, and $10 \%$ level, respectively. P-Values are shown in brackets. 
Table 4. MV-CC GARCH between Cryptocurrencies/Gold and Nikkei

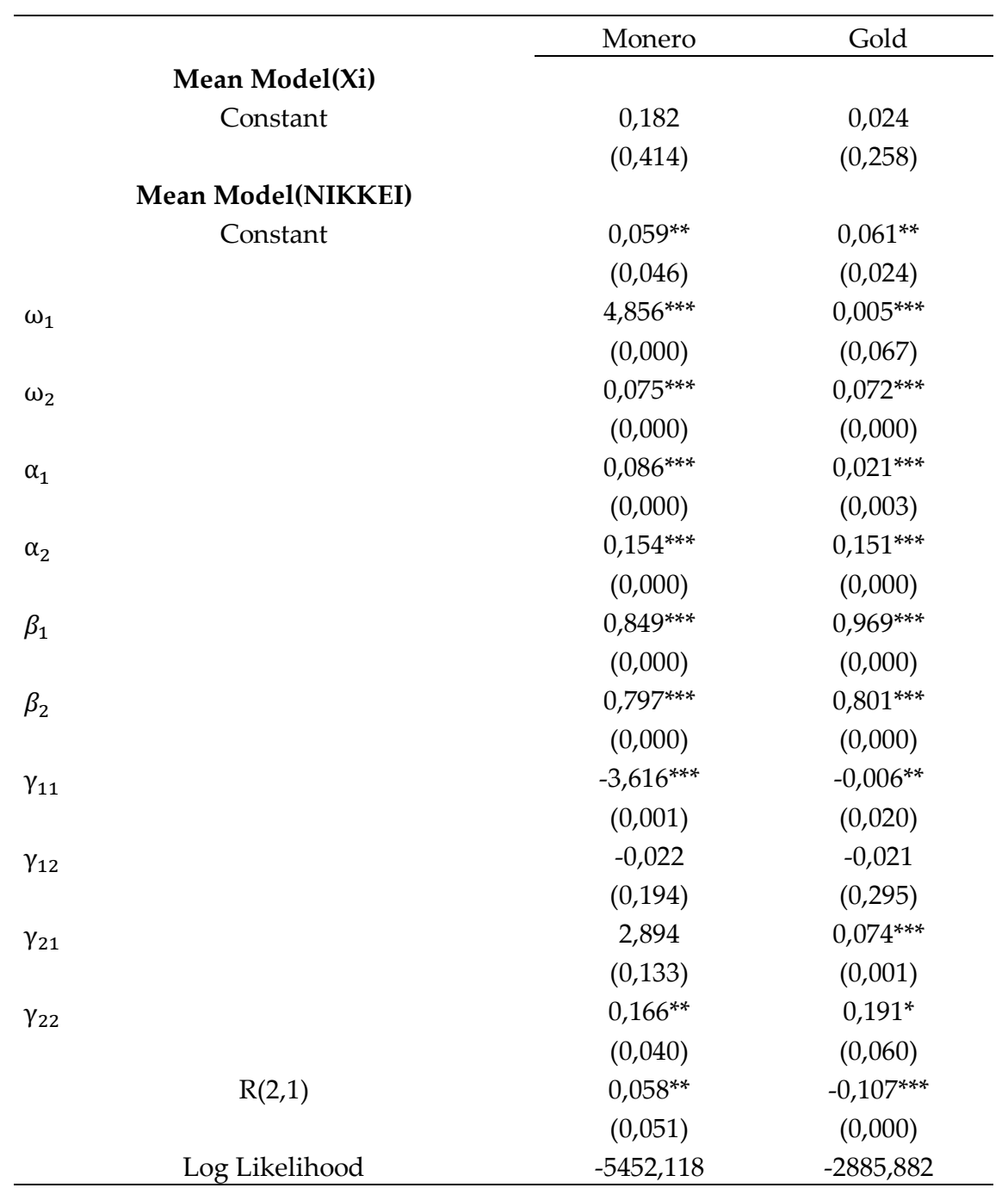

Note: Where $\alpha_{\mathrm{i}}$ and $\beta_{\mathrm{i}}$ represent return volatilities from shocks in own returns reflected respectively by the ARCH and GARCH parameters while $\omega_{\mathrm{i}}$ is a constant. $\gamma_{i t}$ represents coefficients of dummy variables. ${ }^{*}{ }^{* *},{ }^{* * *}$ denote significance at the $1 \%, 5 \%$, and $10 \%$ level, respectively. P-Values are shown in brackets. 
Table 5. MV-DCC GARCH (MV-CC GARCH) between Cryptocurrencies/Gold and DAX30

\begin{tabular}{|c|c|c|c|c|c|c|}
\hline & Bitcoin & Dash & Ethereum & Monero & Gold & Ripple \\
\hline \multicolumn{7}{|l|}{ Mean Model(Xi) } \\
\hline \multirow[t]{2}{*}{ Constant } & $0,261^{* *}$ & $-0,027$ & 0,156 & 0,208 & 3,245 & $-0,228$ \\
\hline & $(0,019)$ & $(0,859)$ & $(0,476)$ & $(0,384)$ & $(0,159)$ & $(0,154)$ \\
\hline \multicolumn{7}{|c|}{ Mean Model(DAX30) } \\
\hline \multirow[t]{2}{*}{ Constant } & $0,056^{* *}$ & $0,051^{* *}$ & $0,055^{* *}$ & $0,054^{*}$ & $5,607^{* *}$ & $0,050^{* *}$ \\
\hline & $(0,022)$ & $(0,038)$ & $(0,031)$ & $(0,058)$ & $(0,023)$ & $(0,042)$ \\
\hline \multirow[t]{2}{*}{$\omega_{1}$} & $1,241^{* * *}$ & $3,153^{* * *}$ & $4,696^{* * *}$ & $5,059^{* * *}$ & $50,776^{*}$ & $3,768^{* * *}$ \\
\hline & $(0,000)$ & $(0,000)$ & $(0,004)$ & $(0,000)$ & $(0,086)$ & $(0,000)$ \\
\hline \multirow[t]{2}{*}{$\omega_{2}$} & $0,039^{* * *}$ & $0,045^{* * *}$ & $0,044^{* * *}$ & $0,047^{* * *}$ & $426,935^{* * *}$ & $0,044^{* * *}$ \\
\hline & $(0,001)$ & $(0,001)$ & $(0,000)$ & $(0,000)$ & $(0,001)$ & $(0,001)$ \\
\hline \multirow{2}{*}{$\alpha_{1}$} & $0,167^{* * *}$ & $0,211^{* * *}$ & $0,143^{* * *}$ & $0,089^{* * *}$ & $0,021^{* * *}$ & $0,141^{* * *}$ \\
\hline & $(0,000)$ & $(0,000)$ & $(0,000)$ & $(0,000)$ & $(0,002)$ & $(0,000)$ \\
\hline \multirow[t]{2}{*}{$\alpha_{2}$} & $0,108^{* * *}$ & $0,113^{* * *}$ & $0,113^{* * *}$ & $0,117^{* * *}$ & $0,105^{* * *}$ & 0,111 \\
\hline & $(0,000)$ & $(0,000)$ & $(0,000)$ & $(0,000)$ & $(0,000)$ & $(0,000)$ \\
\hline \multirow[t]{2}{*}{$\beta_{1}$} & $0,794^{* * *}$ & $0,747^{* * *}$ & $0,782^{* * *}$ & $0,845^{* * *}$ & $0,969^{* * *}$ & $0,803^{* * *}$ \\
\hline & $(0,000)$ & $(0,000)$ & $(0,000)$ & $(0,000)$ & $(0,000)$ & $(0,000)$ \\
\hline \multirow[t]{2}{*}{$\beta_{2}$} & $0,858^{* * *}$ & $0,845^{* * *}$ & $0,846^{* * *}$ & $0,840^{* * *}$ & $0,853^{* * *}$ & $0,847^{* * *}$ \\
\hline & $(0,000)$ & $(0,000)$ & $(0,000)$ & $(0,000)$ & $(0,000)$ & $(0,000)$ \\
\hline \multirow[t]{2}{*}{$\gamma_{11}$} & 0,254 & $-0,579$ & $-2,972^{* *}$ & $-3,760^{* * *}$ & $-57,869^{* *}$ & $-2,769^{* * *}$ \\
\hline & $(0,593)$ & $(0,524)$ & $(0,015)$ & $(0,001)$ & $(0,042)$ & $(0,000)$ \\
\hline \multirow[t]{2}{*}{$\gamma_{12}$} & $-0,002$ & $-0,004$ & $-0,003$ & $-0,003$ & $-14,855$ & $-0,003$ \\
\hline & $(0,871)$ & $(0,795)$ & $(0,847)$ & $(0,830)$ & $(0,925)$ & $(0,843)$ \\
\hline \multirow{2}{*}{$\gamma_{21}$} & $3,384^{* * *}$ & $15,952^{* * *}$ & $4,731^{*}$ & 2,300 & $701,878^{* * *}$ & 2,151 \\
\hline & $(0,007)$ & $(0,004)$ & $(0,079)$ & $(0,157)$ & $(0,002)$ & $(0,158)$ \\
\hline \multirow{2}{*}{$\gamma_{22}$} & $0,195^{* *}$ & $0,223^{* *}$ & $0,209^{* *}$ & $0,214^{* *}$ & $2328,270^{* *}$ & $0,211^{* *}$ \\
\hline & $(0,015)$ & $(0,020)$ & $(0,020)$ & $(0,019)$ & $(0,031)$ & $(0,017)$ \\
\hline \multirow[t]{2}{*}{$\mathrm{DCC}(\mathrm{A})$} & $0,020^{* * *}$ & $0,076^{* *}$ & $0,032^{* *}$ & 0,060 & $0,026^{* *}$ & \\
\hline & $(0,003)$ & $(0,042)$ & $(0,021)$ & $(0,169)$ & $(0,026)$ & \\
\hline \multirow[t]{2}{*}{$\mathrm{DCC}(\mathrm{B})$} & $0,974^{* * *}$ & $0,424^{* * *}$ & $0,870^{* * *}$ & $0,552^{*}$ & $0,969^{* * *}$ & \\
\hline & $(0,000)$ & $(0,010)$ & $(0,000)$ & $(0,071)$ & $(0,000)$ & \\
\hline \multirow[t]{2}{*}{$\mathrm{R}(2,1)$} & & & & & & $0,101^{* * *}$ \\
\hline & & & & & & $(0,000)$ \\
\hline Log Likelihood & $-4723,858$ & $-5150,197$ & $-5219,247$ & $-5349,300$ & $-12897,692$ & $-5186,312$ \\
\hline
\end{tabular}

Note: Where $\alpha_{\mathrm{i}}$ and $\beta_{\mathrm{i}}$ represent return volatilities from shocks in own returns reflected respectively by the ARCH and GARCH parameters while $\omega_{\mathrm{i}}$ is a constant. $\gamma_{i t}$ represents coefficients of dummy variables. ${ }^{*}, * * * *$ denote significance at the $1 \%, 5 \%$, and $10 \%$ level, respectively. P-Values are shown in brackets. 
Table 6. MV-DCC GARCH (MV-CC GARCH) between Cryptocurrencies/Gold and CAC40

\begin{tabular}{|c|c|c|c|c|c|c|}
\hline & Bitcoin & Dash & Ethereum & Gold & Monero & Ripple \\
\hline \multicolumn{7}{|l|}{ Mean Model(Xi) } \\
\hline \multirow[t]{2}{*}{ Constant } & $0,260^{* *}$ & $-0,019$ & 0,153 & 0,028 & 0,186 & $-0,224$ \\
\hline & $(0,015)$ & $(0,910)$ & $(0,416)$ & $(0,167)$ & $(0,429)$ & $(0,228)$ \\
\hline \multicolumn{7}{|c|}{ Mean Model(CAC40) } \\
\hline \multirow[t]{2}{*}{ Constant } & $0,067^{* * *}$ & $0,064^{* * *}$ & $0,067^{* * *}$ & $0,066^{* * *}$ & $0,064^{* * *}$ & $0,062^{* * *}$ \\
\hline & $(0,004)$ & $(0,005)$ & $(0,004)$ & $(0,004)$ & $(0,005)$ & $(0,006)$ \\
\hline \multirow[t]{2}{*}{$\omega_{1}$} & $1,230^{* * *}$ & $3,142^{* * *}$ & $4,584^{* * *}$ & $0,005^{* * *}$ & $4,850^{* * *}$ & $3,775^{* * *}$ \\
\hline & $(0,000)$ & $(0,000)$ & $(0,001)$ & $(0,097)$ & $(0,002)$ & $(0,000)$ \\
\hline \multirow[t]{2}{*}{$\omega_{2}$} & $0,046^{* * *}$ & $0,052^{* * *}$ & $0,051^{* * *}$ & $0,050^{* * *}$ & $0,052^{* * *}$ & $0,051^{* * *}$ \\
\hline & $(0,000)$ & $(0,000)$ & $(0,000)$ & $(0,000)$ & $(0,000)$ & $(0,000)$ \\
\hline \multirow[t]{2}{*}{$\alpha_{1}$} & $0,166^{* * *}$ & $0,211^{* * *}$ & $0,142^{* * *}$ & $0,023^{* * *}$ & $0,087^{* * *}$ & $0,141^{* * *}$ \\
\hline & $(0,000)$ & $(0,000)$ & $(0,000)$ & $(0,001)$ & $(0,000)$ & $(0,000)$ \\
\hline \multirow[t]{2}{*}{$\alpha_{2}$} & $0,186^{* * *}$ & $0,197^{* * *}$ & $0,193^{* * *}$ & $0,184^{* * *}$ & $0,196^{* * *}$ & $0,195^{* * *}$ \\
\hline & $(0,000)$ & $(0,000)$ & $(0,000)$ & $(0,000)$ & $(0,000)$ & $(0,000)$ \\
\hline \multirow[t]{2}{*}{$\beta_{1}$} & $0,795^{* * *}$ & $0,747^{* * *}$ & $0,785^{* * *}$ & $0,968^{* * *}$ & $0,849^{* * *}$ & $0,803^{* * *}$ \\
\hline & $(0,000)$ & $(0,000)$ & $(0,000)$ & $(0,000)$ & $(0,000)$ & $(0,000)$ \\
\hline \multirow[t]{2}{*}{$\beta_{2}$} & $0,785^{* * *}$ & $0,768^{* * *}$ & $0,771^{* * *}$ & $0,778^{* * *}$ & $0,768^{* * *}$ & $0,769^{* * *}$ \\
\hline & $(0,000)$ & $(0,000)$ & $(0,000)$ & $(0,000)$ & $(0,000)$ & $(0,000)$ \\
\hline \multirow[t]{2}{*}{$\gamma_{11}$} & 0,252 & $-0,559$ & $-2,899^{* * *}$ & $-0,006^{* * *}$ & $-3,605^{* * *}$ & $-2,773^{* * *}$ \\
\hline & $(0,597)$ & $(0,521)$ & $(0,005)$ & $(0,010)$ & $(0,005)$ & $(0,000)$ \\
\hline \multirow{2}{*}{$\gamma_{12}$} & 0,002 & 0,001 & 0,001 & 0,003 & 0,001 & 0,001 \\
\hline & $(0,877)$ & $(0,953)$ & $(0,961)$ & $(0,880)$ & $(0,935)$ & $(0,932)$ \\
\hline \multirow[t]{2}{*}{$\gamma_{21}$} & $3,547^{* * *}$ & $16,429^{* * *}$ & $5,080^{* *}$ & $0,073^{* * *}$ & 2,784 & 2,320 \\
\hline & $(0,010)$ & $(0,004)$ & $(0,040)$ & $(0,003)$ & $(0,171)$ & $(0,163)$ \\
\hline \multirow[t]{2}{*}{$\gamma_{22}$} & $0,154^{* *}$ & $0,170^{* *}$ & $0,161^{* *}$ & $0,171^{* *}$ & $0,164^{*}$ & $0,162^{* *}$ \\
\hline & $(0,047)$ & $(0,022)$ & $(0,033)$ & $(0,027)$ & $(0,055)$ & $(0,034)$ \\
\hline \multirow[t]{2}{*}{$\mathrm{DCC}(\mathrm{A})$} & $0,015^{* *}$ & $0,095^{* *}$ & $0,040^{* * *}$ & $0,044^{* * *}$ & & \\
\hline & $(0,016)$ & $(0,016)$ & $(0,010)$ & $(0,001)$ & & \\
\hline \multirow[t]{2}{*}{$\mathrm{DCC}(\mathrm{B})$} & $0,981^{* * *}$ & $0,456^{* * *}$ & $0,840^{* * *}$ & $0,944^{* * *}$ & & \\
\hline & $(0,000)$ & $(0,001)$ & $(0,000)$ & $(0,000)$ & & \\
\hline \multirow[t]{2}{*}{$\mathrm{R}(2,1)$} & & & & & $0,077^{* * *}$ & $0,080^{* * *}$ \\
\hline & & & & & $(0,002)$ & $(0,002)$ \\
\hline Log Likelihood & $-4661,395$ & $-5085,064$ & $-5152,885$ & $-2695,404$ & $-5285,840$ & $-5124,528$ \\
\hline
\end{tabular}

Note: Where $\alpha_{\mathrm{i}}$ and $\beta_{\mathrm{i}}$ represent return volatilities from shocks in own returns reflected respectively by the ARCH and GARCH parameters while $\omega_{\mathrm{i}}$ is a constant. $\gamma_{i t}$ represents coefficients of dummy variables. ${ }^{*}, * * * *$ denote significance at the $1 \%, 5 \%$, and $10 \%$ level, respectively. P-Values are shown in brackets. Xi corresponds to the effect of past Crypto/Gold market performance. 
Table 7. MV-DCC GARCH between Cryptocurrencies/Gold and FTSE MIB

\begin{tabular}{|c|c|c|c|c|c|c|}
\hline & Bitcoin & Dash & Ethereum & Monero & Ripple & Gold \\
\hline \multicolumn{7}{|l|}{ Mean Model (Xi) } \\
\hline \multirow[t]{2}{*}{ Constant } & $0,255^{* *}$ & $-0,024$ & 0,128 & 0,213 & $-0,228$ & 0,029 \\
\hline & $(0,031)$ & $(0,893)$ & $(0,544)$ & $(0,319)$ & $(0,169)$ & $(0,168)$ \\
\hline \multicolumn{7}{|c|}{ Mean Model (FTSE MIB) } \\
\hline \multirow[t]{2}{*}{ Constant } & $0,056^{*}$ & $0,049^{*}$ & $0,054^{*}$ & $0,052^{*}$ & $0,052^{*}$ & $0,053^{*}$ \\
\hline & $(0,068)$ & $(0,080)$ & $(0,070)$ & $(0,108)$ & $(0,105)$ & $(0,087)$ \\
\hline \multirow[t]{2}{*}{$\omega_{1}$} & $1,210^{* * *}$ & $3,177^{* * *}$ & $4,416^{* * *}$ & $4,865^{* * *}$ & $3,802^{* * *}$ & $0,005^{* * *}$ \\
\hline & $(0,000)$ & $(0,000)$ & $(0,006)$ & $(0,000)$ & $(0,000)$ & $(0,091)$ \\
\hline \multirow[t]{2}{*}{$\omega_{2}$} & $0,050^{* * *}$ & $0,067^{* * *}$ & $0,061^{* * *}$ & $0,065^{* * *}$ & $0,065^{* * *}$ & $0,058^{* * *}$ \\
\hline & $(0,003)$ & $(0,002)$ & $(0,003)$ & $(0,006)$ & $(0,003)$ & $(0,005)$ \\
\hline \multirow[t]{2}{*}{$\alpha_{1}$} & $0,164^{* * *}$ & $0,206^{* * *}$ & $0,138^{* * *}$ & $0,088^{* * *}$ & $0,143^{* * *}$ & $0,021^{* * *}$ \\
\hline & $(0,000)$ & $(0,000)$ & $(0,000)$ & $(0,000)$ & $(0,000)$ & $(0,001)$ \\
\hline \multirow[t]{2}{*}{$\alpha_{2}$} & $0,120^{* * *}$ & $0,141^{* * *}$ & $0,132^{* * *}$ & $0,139^{* * *}$ & $0,139^{* * *}$ & $0,130^{* * *}$ \\
\hline & $(0,000)$ & $(0,000)$ & $(0,000)$ & $(0,000)$ & $(0,000)$ & $(0,000)$ \\
\hline \multirow[t]{2}{*}{$\beta_{1}$} & $0,798^{* * *}$ & $0,751^{* * *}$ & $0,791^{* * *}$ & $0,849^{* * *}$ & $0,801^{* * *}$ & $0,970^{* * *}$ \\
\hline & $(0,000)$ & $(0,000)$ & $(0,000)$ & $(0,000)$ & $(0,000)$ & $(0,000)$ \\
\hline \multirow[t]{2}{*}{$\beta_{2}$} & $0,856^{* * *}$ & $0,827^{* * *}$ & $0,837^{* * *}$ & $0,830^{* * *}$ & $0,829^{* * *}$ & $0,841^{* * *}$ \\
\hline & $(0,000)$ & $(0,000)$ & $(0,000)$ & $(0,000)$ & $(0,000)$ & $(0,000)$ \\
\hline \multirow[t]{2}{*}{$\gamma_{11}$} & 0,245 & $-0,527$ & $-2,801^{* *}$ & $-3,596^{* * *}$ & $-2,778^{* * *}$ & $-0,006^{* * *}$ \\
\hline & $(0,589)$ & $(0,544)$ & $(0,025)$ & $(0,002)$ & $(0,000)$ & $(0,022)$ \\
\hline \multirow{2}{*}{$\gamma_{12}$} & $-0,013$ & $-0,014$ & $-0,014$ & $-0,014$ & $-0,014$ & $-0,014$ \\
\hline & $(0,505)$ & $(0,490)$ & $(0,465)$ & $(0,546)$ & $(0,501)$ & $(0,434)$ \\
\hline \multirow[t]{2}{*}{$\gamma_{21}$} & $3,482^{* * *}$ & $15,086^{* *}$ & $4,816^{* *}$ & 2,203 & 1,982 & $0,071^{* * *}$ \\
\hline & $(0,008)$ & $(0,016)$ & $(0,062)$ & $(0,202)$ & $(0,191)$ & $(0,001)$ \\
\hline \multirow[t]{2}{*}{$\gamma_{22}$} & $0,251^{* *}$ & $0,272^{* *}$ & $0,252^{* *}$ & $0,257^{*}$ & $0,258^{* *}$ & $0,267^{* *}$ \\
\hline & $(0,056)$ & $(0,021)$ & $(0,048)$ & $(0,075)$ & $(0,056)$ & $(0,042)$ \\
\hline \multirow[t]{2}{*}{$\mathrm{DCC}(\mathrm{A})$} & $0,019^{* *}$ & $0,082^{* *}$ & $0,049^{* * *}$ & $0,038^{* *}$ & $0,056^{* *}$ & $0,013^{* *}$ \\
\hline & $(0,026)$ & $(0,023)$ & $(0,006)$ & $(0,044)$ & $(0,054)$ & $(0,119)$ \\
\hline \multirow[t]{2}{*}{$\mathrm{DCC}(\mathrm{B})$} & $0,977^{* * *}$ & $0,632^{* * *}$ & $0,830^{* * *}$ & $0,877^{* * *}$ & $0,813^{* * *}$ & $0,984^{* * *}$ \\
\hline & $(0,000)$ & $(0,000)$ & $(0,000)$ & $(0,000)$ & $(0,000)$ & $(0,000)$ \\
\hline Log Likelihood & $-4959,082$ & $-5388,057$ & $-5450,232$ & $-5584,253$ & $-5422,308$ & $-3005,918$ \\
\hline
\end{tabular}

Note: Where $\alpha_{\mathrm{i}}$ and $\beta_{\mathrm{i}}$ represent return volatilities from shocks in own returns reflected respectively by the ARCH and GARCH parameters while $\omega_{\mathrm{i}}$ is a constant. $\gamma_{i t}$ represents coefficients of dummy variables. ${ }^{*}, * * * *$ denote significance at the $1 \%, 5 \%$, and $10 \%$ level, respectively. P-Values are shown in brackets. 
Table 8. MV-DCC GARCH (MV-CC GARCH) between Cryptocurrencies/Gold and S\&P TSX

\begin{tabular}{|c|c|c|c|c|c|c|}
\hline & Bitcoin & Ethereum & Ripple & Gold & Dash & Monero \\
\hline \multicolumn{7}{|l|}{ Mean Model(Xi) } \\
\hline \multirow[t]{2}{*}{$\mathrm{Xi}(1)$} & 0,025 & $0,066^{*}$ & $-0,069^{*}$ & $-0,007$ & 0,000 & $-0,059^{*}$ \\
\hline & $(0,471)$ & $(0,058)$ & $(0,055)$ & $(0,833)$ & $(0,992)$ & $(0,080)$ \\
\hline \multirow[t]{2}{*}{ SP TSX(1) } & $0,416^{* *}$ & $0,623^{*}$ & $1,336^{* * *}$ & 0,039 & 0,128 & $0,636^{* *}$ \\
\hline & $(0,051)$ & $(0,055)$ & $(0,000)$ & $(0,126)$ & $(0,565)$ & $(0,019)$ \\
\hline \multirow[t]{2}{*}{ Constant } & $0,203^{*}$ & 0,153 & $-0,427^{* *}$ & 0,029 & $-0,023$ & 0,175 \\
\hline & $(0,078)$ & $(0,428)$ & $(0,019)$ & $(0,229)$ & $(0,903)$ & $(0,432)$ \\
\hline \multicolumn{7}{|c|}{ Mean Model (SP TSX) } \\
\hline \multirow[t]{2}{*}{$\mathrm{Xi}(1)$} & 0,004 & $-0,001$ & 0,001 & $-0,016$ & $-0,001$ & $-0,001$ \\
\hline & $(0,170)$ & $(0,665)$ & $(0,738)$ & $(0,338)$ & $(0,762)$ & $(0,576)$ \\
\hline \multirow[t]{2}{*}{ SP TSX(1) } & $0,072^{* *}$ & $0,076^{* *}$ & $0,078^{* * *}$ & $0,063^{*}$ & $0,071^{* *}$ & $0,071^{* *}$ \\
\hline & $(0,025)$ & $(0,029)$ & $(0,011)$ & $(0,069)$ & $(0,022)$ & $(0,035)$ \\
\hline \multirow[t]{2}{*}{ Constant } & $0,043^{* * *}$ & $0,046^{* * *}$ & $0,043^{* * *}$ & $0,051^{* * *}$ & $0,045^{* * *}$ & $0,045^{* * *}$ \\
\hline & $(0,003)$ & $(0,001)$ & $(0,002)$ & $(0,001)$ & $(0,001)$ & $(0,002)$ \\
\hline \multirow{2}{*}{$\omega_{1}$} & $1,159^{* * *}$ & $4,048^{* * *}$ & $5,578^{* * *}$ & $0,005^{* * *}$ & $3,138^{* * *}$ & $5,475^{* * *}$ \\
\hline & $(0,000)$ & $(0,001)$ & $(0,000)$ & $(0,091)$ & $(0,000)$ & $(0,001)$ \\
\hline \multirow[t]{2}{*}{$\omega_{2}$} & $0,022^{* * *}$ & $0,024^{* * *}$ & $0,024^{* * *}$ & $0,026^{* * *}$ & $0,026^{* * *}$ & $0,026^{* * *}$ \\
\hline & $(0,000)$ & $(0,000)$ & $(0,000)$ & $(0,000)$ & $(0,000)$ & $(0,000)$ \\
\hline \multirow[t]{2}{*}{$\alpha_{1}$} & $0,165^{* * *}$ & $0,137^{* * *}$ & $0,260^{* * *}$ & $0,022^{* * *}$ & $0,209^{* * *}$ & $0,089^{* * *}$ \\
\hline & $(0,000)$ & $(0,000)$ & $(0,000)$ & $(0,003)$ & $(0,000)$ & $(0,000)$ \\
\hline \multirow[t]{2}{*}{$\alpha_{2}$} & $0,204^{* * *}$ & $0,206^{* * *}$ & $0,211^{* * *}$ & $0,230^{* * *}$ & $0,218^{* * *}$ & $0,220^{* * *}$ \\
\hline & $(0,000)$ & $(0,000)$ & $(0,000)$ & $(0,000)$ & $(0,000)$ & $(0,000)$ \\
\hline \multirow[t]{2}{*}{$\beta_{1}$} & $0,799 * * *$ & $0,799 * * *$ & $0,688^{* * *}$ & $0,968^{* * *}$ & $0,747^{* * *}$ & $0,838^{* * *}$ \\
\hline & $(0,000)$ & $(0,000)$ & $(0,000)$ & $(0,000)$ & $(0,000)$ & $(0,000)$ \\
\hline \multirow[t]{2}{*}{$\beta_{2}$} & $0,757^{* * *}$ & $0,751^{* * *}$ & $0,745^{* * *}$ & $0,728^{* * *}$ & $0,732^{* * *}$ & $0,732^{* * *}$ \\
\hline & $(0,000)$ & $(0,000)$ & $(0,000)$ & $(0,000)$ & $(0,000)$ & $(0,000)$ \\
\hline \multirow{2}{*}{$\gamma_{11}$} & 0,248 & $-2,506^{* * *}$ & $-3,825^{* * *}$ & $-0,007^{* *}$ & $-0,527$ & $-4,083^{* * *}$ \\
\hline & $(0,634)$ & $(0,011)$ & $(0,000)$ & $(0,014)$ & $(0,580)$ & $(0,004)$ \\
\hline \multirow[t]{2}{*}{$\gamma_{12}$} & $-0,014^{* * *}$ & $-0,015^{* *}$ & $-0,015^{* * *}$ & $-0,016^{* * *}$ & $-0,016^{* * *}$ & $-0,016^{* * *}$ \\
\hline & $(0,008)$ & $(0,013)$ & $(0,011)$ & $(0,007)$ & $(0,012)$ & $(0,008)$ \\
\hline \multirow[t]{2}{*}{$\gamma_{21}$} & $3,197^{* *}$ & 3,537 & $-1,037$ & $0,079 * * *$ & $15,596^{* * *}$ & 2,166 \\
\hline & $(0,025)$ & $(0,148)$ & $(0,582)$ & $(0,001)$ & $(0,007)$ & $(0,262)$ \\
\hline \multirow{2}{*}{$\gamma_{22}$} & 0,014 & 0,015 & 0,014 & 0,013 & 0,013 & 0,014 \\
\hline & $(0,345)$ & $(0,405)$ & $(0,366)$ & $(0,477)$ & $(0,452)$ & $(0,434)$ \\
\hline \multirow[t]{2}{*}{$\mathrm{DCC}(\mathrm{A})$} & $0,011^{* *}$ & $0,023^{* * *}$ & $0,009^{* * *}$ & $0,081^{* * *}$ & & \\
\hline & $(0,015)$ & $(0,100)$ & $(0,105)$ & $(0,000)$ & & \\
\hline \multirow[t]{2}{*}{$\mathrm{DCC}(\mathrm{B})$} & $0,988^{* * *}$ & $0,958^{* * *}$ & $0,990^{* * *}$ & $0,891^{* * *}$ & & \\
\hline & $(0,000)$ & $(0,000)$ & $(0,000)$ & $(0,000)$ & & \\
\hline \multirow[t]{2}{*}{$\mathrm{R}(2,1)$} & & & & & $0,092^{* * *}$ & $0,086^{* * *}$ \\
\hline & & & & & $(0,001)$ & $(0,003)$ \\
\hline Log Likelihood & $-4140,296$ & $-4629,266$ & $-4594,603$ & $-2204,242$ & $-4566,223$ & $-4761,837$ \\
\hline
\end{tabular}

Note: Where $\alpha_{\mathrm{i}}$ and $\beta_{\mathrm{i}}$ represent return volatilities from shocks in own returns reflected respectively by the ARCH and GARCH parameters while $\omega_{i}$ is a constant. $\gamma_{i j}$ measures the model asymmetry. *, $* *, * *$ denote significance at the $1 \%, 5 \%$, and $10 \%$ level, respectively. P-Values are shown in brackets. $\mathrm{X} \mathrm{i}$ corresponds to the effect of past Crypto/Gold market performance. SP TSX (i) corresponds to the effect of past index performance 
Table 9. MV-DCC GARCH between Cryptocurrencies/Gold and SSE

\begin{tabular}{|c|c|c|c|c|}
\hline & Bitcoin & Ethereum & Ripple & Gold \\
\hline \multicolumn{5}{|c|}{ Mean Model (Xi) } \\
\hline \multirow{2}{*}{ Constant } & $0,229^{*}$ & 0,117 & $-0,252$ & 0,031 \\
\hline & $(0,076)$ & $(0,484)$ & $(0,126)$ & $(0,157)$ \\
\hline \multicolumn{5}{|c|}{ Mean Model (SSE) } \\
\hline \multirow[t]{2}{*}{ Constant } & 0,017 & 0,013 & 0,011 & 0,010 \\
\hline & $(0,484)$ & $(0,604)$ & $(0,668)$ & $(0,665)$ \\
\hline \multirow[t]{2}{*}{$\omega_{1}$} & $1,186^{* * *}$ & $4,545^{* * *}$ & $3,792^{* * *}$ & $0,005^{* * *}$ \\
\hline & $(0,000)$ & $(0,003)$ & $(0,000)$ & $(0,104)$ \\
\hline \multirow[t]{2}{*}{$\omega_{2}$} & $0,009^{* *}$ & $0,009^{* * *}$ & $0,009^{* * *}$ & $0,008^{* * *}$ \\
\hline & $(0,017)$ & $(0,007)$ & $(0,008)$ & $(0,001)$ \\
\hline \multirow[t]{2}{*}{$\alpha_{1}$} & $0,163^{* * *}$ & $0,147^{* * *}$ & $0,144^{* * *}$ & $0,022^{* * *}$ \\
\hline & $(0,000)$ & $(0,000)$ & $(0,000)$ & $(0,006)$ \\
\hline \multirow[t]{2}{*}{$\alpha_{2}$} & $0,063^{* * *}$ & $0,064^{* * *}$ & $0,061^{* * *}$ & $0,059^{* * *}$ \\
\hline & $(0,000)$ & $(0,000)$ & $(0,000)$ & $(0,000)$ \\
\hline \multirow[t]{2}{*}{$\beta_{1}$} & $0,799^{* * *}$ & $0,781^{* * *}$ & $0,800^{* * *}$ & $0,969^{* * *}$ \\
\hline & $(0,000)$ & $(0,000)$ & $(0,000)$ & $(0,000)$ \\
\hline \multirow[t]{2}{*}{$\beta_{2}$} & $0,929^{* * *}$ & $0,928^{* * *}$ & $0,931^{* * *}$ & $0,933^{* * *}$ \\
\hline & $(0,000)$ & $(0,000)$ & $(0,000)$ & $(0,000)$ \\
\hline \multirow[t]{2}{*}{$\gamma_{11}$} & 0,256 & $-2,864^{* *}$ & $-2,796^{* * *}$ & $-0,006^{* *}$ \\
\hline & $(0,601)$ & $(0,018)$ & $(0,000)$ & $(0,013)$ \\
\hline \multirow[t]{2}{*}{$\gamma_{12}$} & $-0,001$ & 0,000 & $-0,001$ & $-0,001$ \\
\hline & $(0,927)$ & $(0,951)$ & $(0,927)$ & $(0,910)$ \\
\hline \multirow[t]{2}{*}{$\gamma_{21}$} & $4,039^{* * *}$ & $5,707^{*}$ & 2,589 & $0,067^{* * *}$ \\
\hline & $(0,010)$ & $(0,058)$ & $(0,152)$ & $(0,003)$ \\
\hline \multirow[t]{2}{*}{$\gamma_{22}$} & $0,114^{* * *}$ & $0,114^{* * *}$ & $0,116^{* * *}$ & $0,112^{* * *}$ \\
\hline & $(0,011)$ & $(0,012)$ & $(0,011)$ & $(0,004)$ \\
\hline \multirow[t]{2}{*}{$\operatorname{DCC}(\mathrm{A})$} & $0,023^{* *}$ & $0,026^{* * *}$ & $-0,008^{* * *}$ & $0,020^{* *}$ \\
\hline & $(0,029)$ & $(0,011)$ & $(0,000)$ & $(0,049)$ \\
\hline \multirow[t]{2}{*}{$\mathrm{DCC}(\mathrm{B})$} & $0,952^{* * *}$ & $0,952^{* * *}$ & $0,956^{* * *}$ & $0,925^{* * *}$ \\
\hline & $(0,000)$ & $(0,000)$ & $(0,000)$ & $(0,000)$ \\
\hline Log Likelihood & $-4734,302$ & $-5228,415$ & $-5199,137$ & $-2795,807$ \\
\hline
\end{tabular}

Note: Where $\alpha_{\mathrm{i}}$ and $\beta_{\mathrm{i}}$ represent return volatilities from shocks in own returns reflected respectively by the ARCH and GARCH parameters while $\omega_{\mathrm{i}}$ is a constant. $\gamma_{\mathrm{ij}}$ measures the model asymmetry. ${ }^{*}$, **, ${ }^{* * *}$ denote significance at the $1 \%, 5 \%$, and $10 \%$ level, respectively. P-Values are shown in brackets. $\mathrm{Xi}$ corresponds to the effect of past Crypto/Gold market performance. SP TSX (i) corresponds to the effect of past index performance 
Besides, tables from 2 to 9 demonstrate the COVID-19 effects on volatility through the $\gamma_{i j}$ coefficients. The first dummies effect related to the period preceding the stock market influence exhibit a negative coefficient for four markets is all significant at a $1 \%$ level. The coefficients of Ethereum, Monero, Ripple and the gold market are negative $\left(\gamma_{11}\right)$. This result indicates that the volatility decreases in Ethereum, Monero, Ripple, and the gold market in the period preceding the stock market influence. The same effect appears to be significant for the Canadian market.

It is also interesting to find that the effect of the second dummies variable related to the succeeding COVID-19 period is significant. All DCC-GARCH tables confirm that the coefficients of $\left(\gamma_{21}\right)$ are positive and significant at a $1 \%$ level, for only two cryptocurrencies: Bitcoin and Dash, and for Gold. This result means that the succeeding period of the COVID-19 crisis increases the volatility for the mentioned digital asset and Gold. The coefficients $\left(\gamma_{22}\right)$ appear to be significant in all cases except for S\&P TSX at least at a level of 10\%. Thus, the empirical result shows that the Covid- 19 crisis increases the volatility of those stock indices.

Figure 3. Dynamic conditional correlations between Bitcoin and stock market indices

Figure 4. Dynamic conditional correlations between Dash and stock market indices
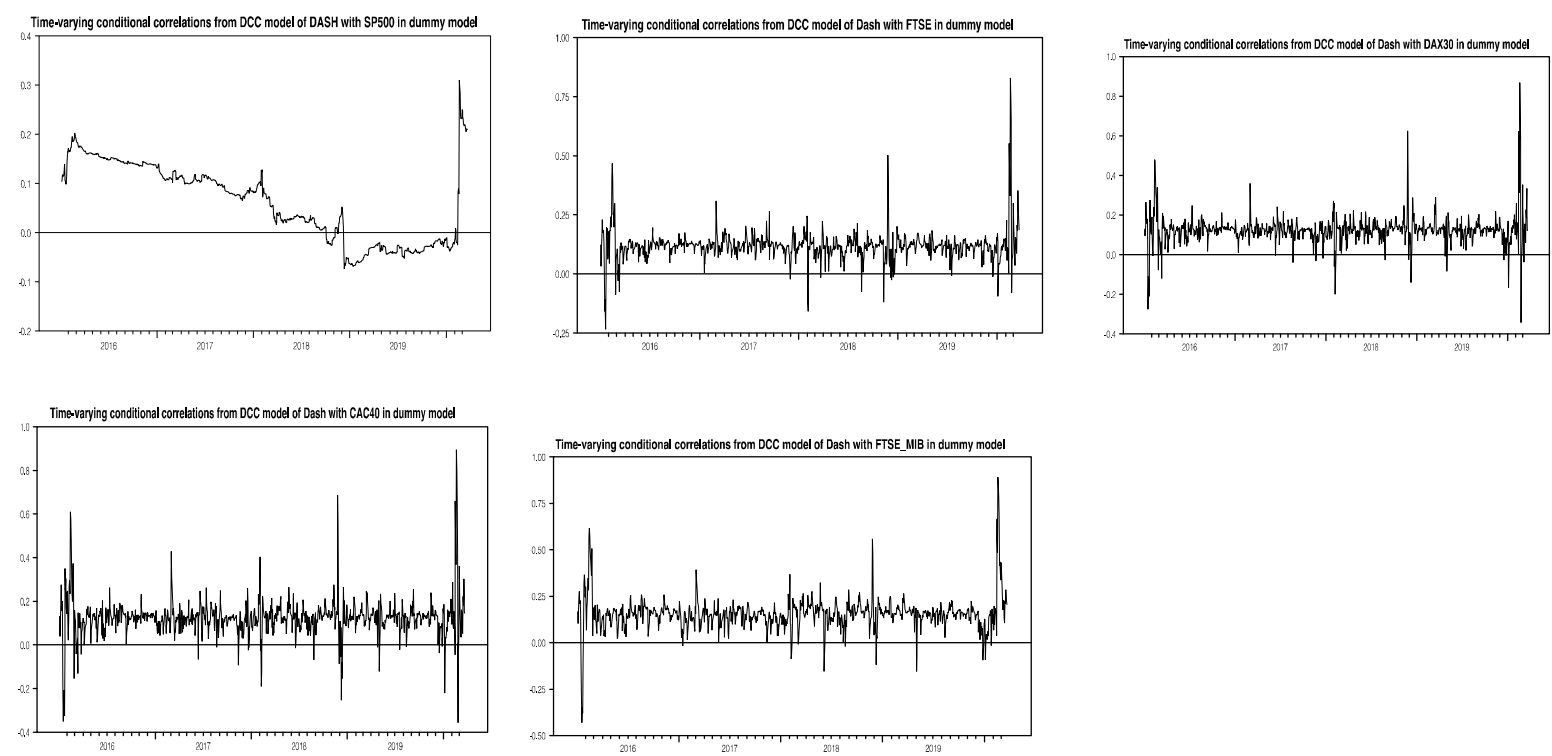

Figure 5. Dynamic conditional correlations between Ethereum and stock market indices
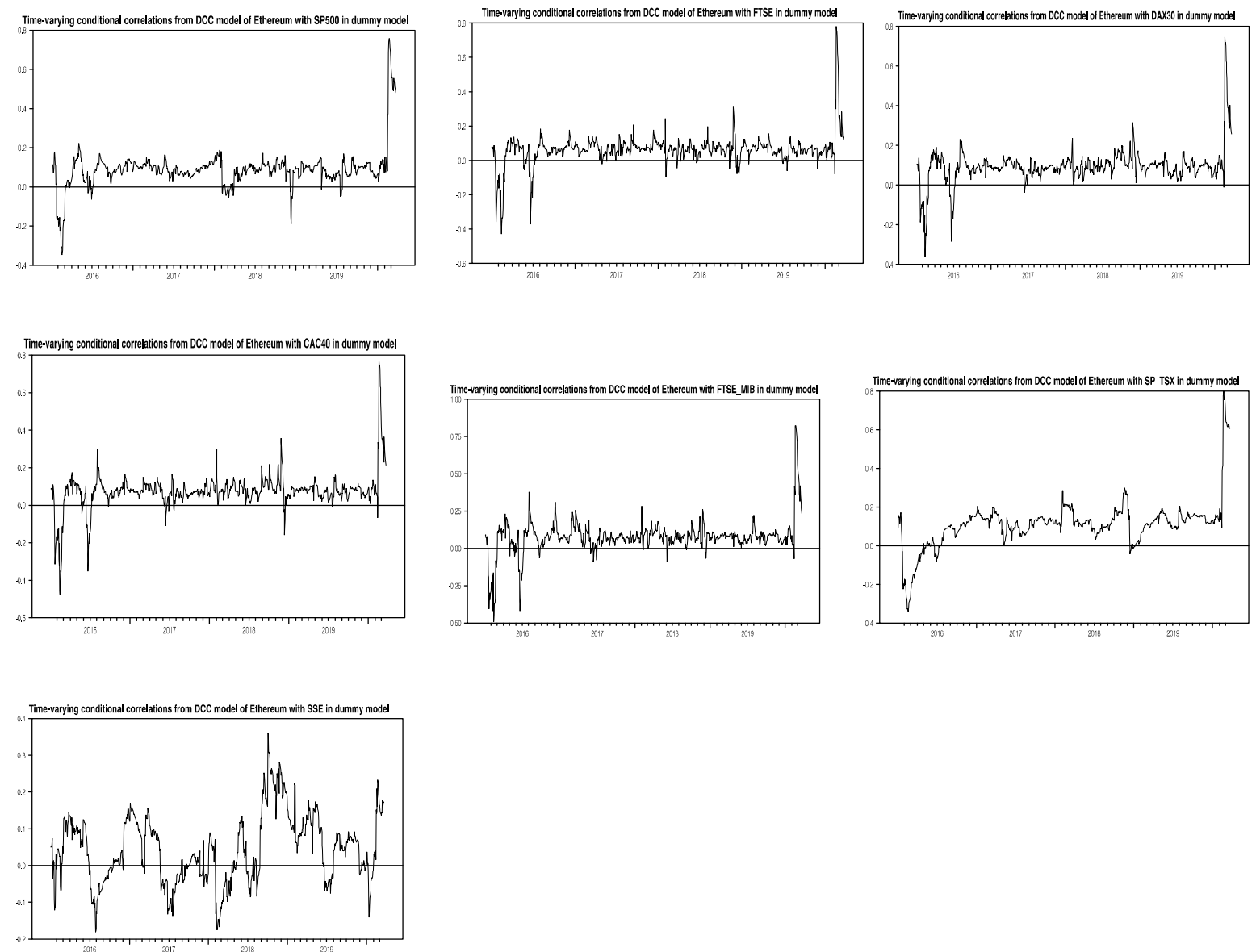
Figure 6. Dynamic conditional correlations between Ripple and stock market indices
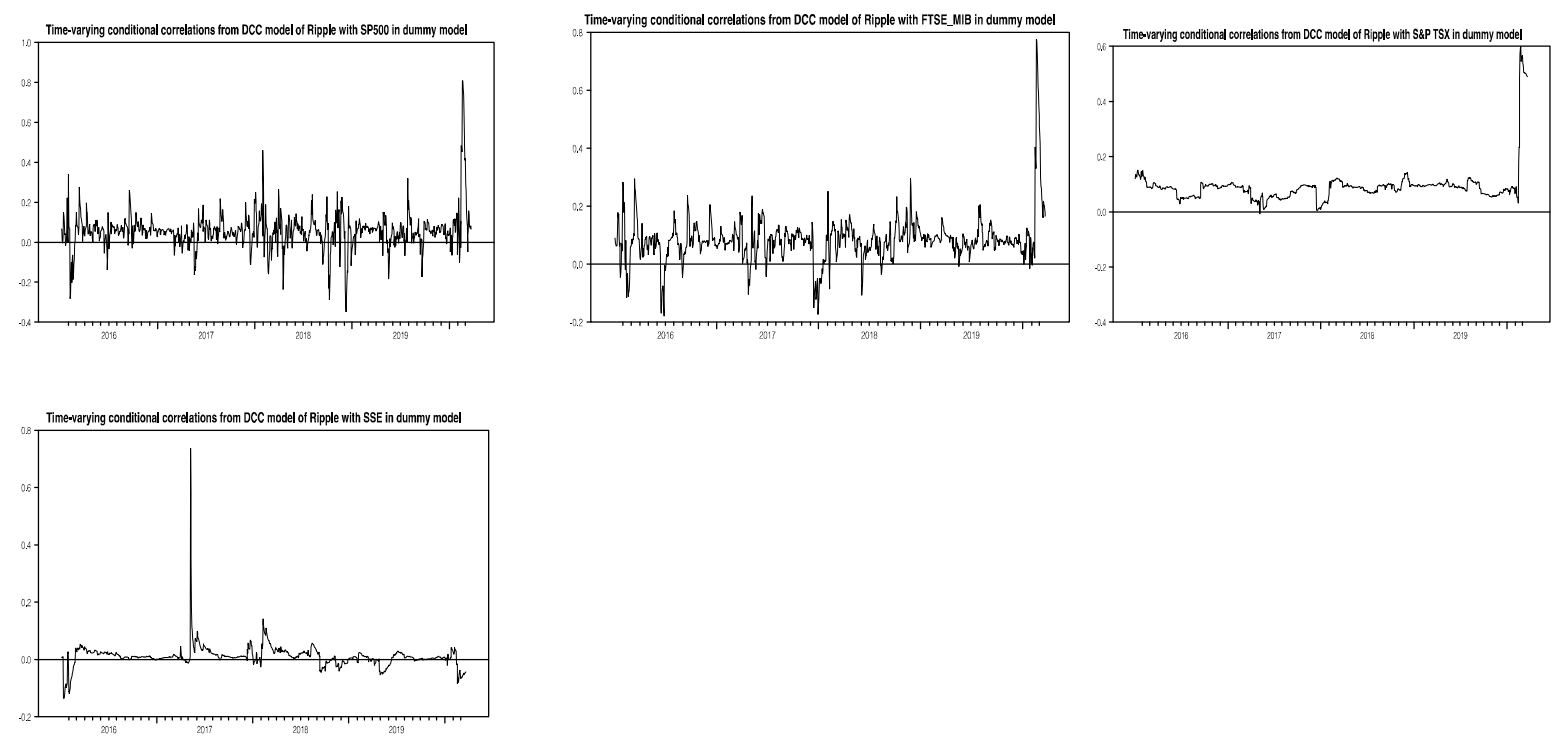

Figure 7. Dynamic conditional correlations between Monero and stock market indices
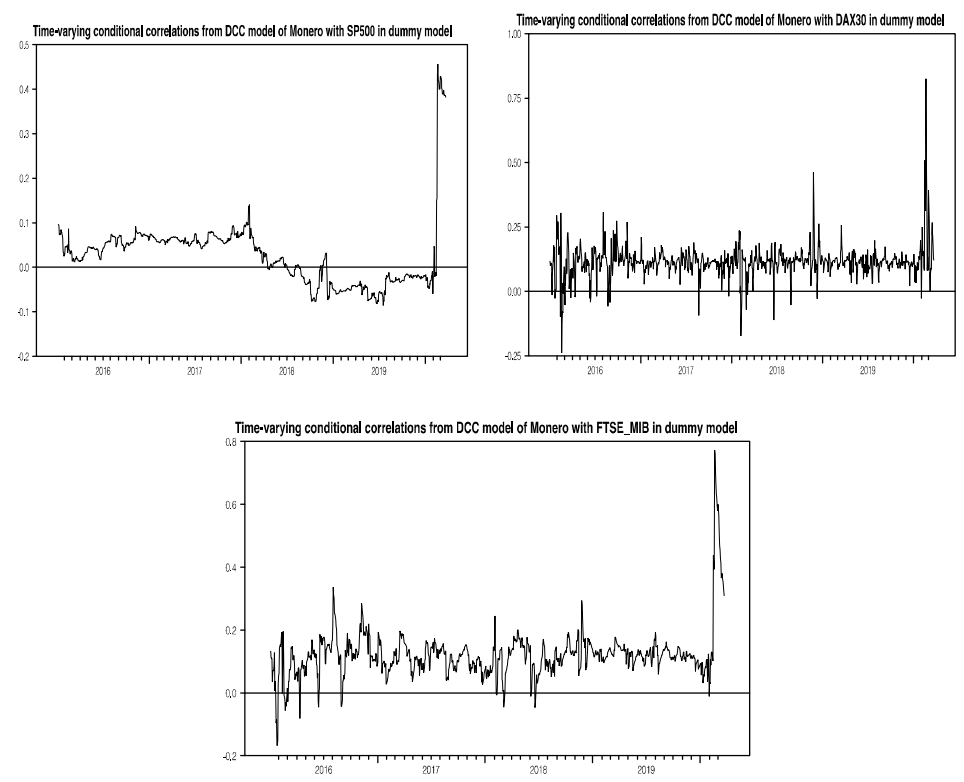

Focusing on the time-varying conditional dependency between cryptocurrencies and stock market indices in Figures from 3 to 8, we show that the dynamic correlations between cryptocurrencies and stock market indices are low before the appearance of the COVID-19. We also discovered that cryptocurrencies are rather separated from other markets. This finding is similar to that of Corbet et al. (2018), Corbet et al. (2019), Aslanidis et al. (2019), Tiwari et al. (2019), and Charfeddine et al. (2020). Dynamic correlations between cryptocurrencies and stock market indices remain high and positive as news of the epidemic COVID-19 virus spreads further beyond China. When focusing on the timevarying conditional correlation between Bitcoin and stock market indices in Figure 3, we show that the dynamic correlation between Bitcoin and stock market indices (S\&P 500, FTSE, DAX 30, CAC 40, FTSE-MIB, and SSE) is negative and low before the COVID-19 pandemic which indicates that the risks 
among these stock markets can be hedged by Bitcoin. This result is consistent with that of Dyhberg (2016) and Guesmi et al. (2019) and inconsistent with that of Bouri et al. (2017), Kajtazi and Moro (2018), and Cherfeddine et al. (2020). Dash and Monero are also considered as hedge assets for US investors before 2020. We suggest also significant benefits for portfolio diversification and risk management when digital assets as Dash, Ethereum, Monero, and Ripple were added. Rounding up the analysis, we explore the relationship between Gold and stock market indices. Based on the results from figure 8 and applying the categorizations of Baur and Lucey (2010), we find that that gold acts as a hedge for US, English, French, German, Italian, and Canadian financial investors. However, it acts as a diversifier asset for Chinese investors. During the COVID-19 outbreak, the conditional correlation between stock indices on the one hand and digital assets and gold, on the other hand, was skyrocketing, except for the couple SSE-Ripple, which confirms the contagion effect of coronavirus between them. Also, Ripple can be considered a haven asset for Chinese investors.

Figure 8. Dynamic conditional correlations between Gold and stock market indices


\section{Conclusion}

Using data relevant to G7 and Chinese stock market indices, five popular cryptocurrencies (Bitcoin, Dash, Ethereum, Monero, and Ripple), and Gold, we have investigated the relationship between the volatilities of traditional and digital assets. The results of the DCC-MVGARCH model identify an important effect of the COVID-19 outbreak. The crypto market became more volatile after the appearance of the COVID-19 in early 2020. Digital assets present almost identical movements of volatility. The stock markets responded to the Coronavirus outbreak as a crypto market with worrying 
volatility, as traders were panic-sold out of fear. Indeed, equities have plummeted and stock market volatility has skyrocketed. Gold is generally less volatile than other commodities but it was volatile this time. Gold is not playing the role of a haven that it has performed in the past. When estimating the dynamic conditional correlations, we find, firstly, that the dynamic correlations between cryptocurrencies and stock market indices are low before the appearance of the COVID-19. We also discovered that cryptocurrencies are rather separated from other markets. Dynamic correlations between cryptocurrencies and stock market indices remain high and positive as news of the epidemic COVID-19 virus spreads further beyond China. Before 2020, the results indicate that the risks among the US, English, German, French, Italian, and Chinese stock markets can be hedged by Bitcoin. Dash and Monero are also considered hedge assets for US investors before the Corona virus pandemic. The findings suggest also significant benefits for portfolio diversification when digital assets as Dash, Ethereum, Monero, and Ripple were added. During the first quarter of 2020, the conditional correlation between stock indices and other assets was skyrocketing, except for the couple SSE-Ripple. Also, Ripple can be considered a haven asset for Chinese investors.

The empirical findings have implications for both institutional and retail investors, as well as financial advisers, and explain why risk spillovers in G7 countries and China remain asymmetric throughout mitigated times. As a result, we may deduce two major management implications. First, decision-makers in the G7 and China should support financial markets whenever there is a threat of collapse. Therefore, the risk of a market crash can be better managed during a crisis. Second, particularly during the COVID-19 crisis, investors might use hedging or haven strategies. From an investing point of view, oil prices may impact stock prices in two ways: directly through corporate cash flows and indirectly through the discount rate. This can be considered as a new potential area for further research. Furthermore, cryptocurrencies serve as a means of exchange, a unit of account, and a store of value, all of which contribute to a better understanding of the economy's susceptibility to shocks. As a result, the stock market, cryptocurrency, and commodity behavior are critical to policymaking and boosting economic activity, particularly during a pandemic.

Availability of Data and Materials: Daily time series data are collected for stock prices of the United States (S\&P500), France (CAC40), Germany (DAX30), the United Kingdom (FTSE 100), Italy (MIB 30), Japan (Nikkei 225), Canada (SP-TSX) and China (SSE) from DataStream. From the same database, we extracted the gold prices. Data concerning the five studied cryptocurrencies (Bitcoin, Dash, Ethereum, Ripple, and Monero) was collected from the Coin Market Cap basis. In case of request, I provide all the requested data.

Acknowledgments: The authors would like to thank the Editor and the referees for careful reading and comments, which greatly improved the paper.

Author Contributions: Both authors equally contributed to the article.

Funding: This research received no external funding.

Conflicts of Interest: The authors declare no conflict of interest.

\section{References}

Aslanidis N., Bariviera A-F., Martínez-Ibañez O., 2019. An analysis of cryptocurrencies conditional cross correlations, Finance Research Letters, 31, 130-137.

Baur, D., and Hoang, Lai., 2020. A Crypto Safe Haven against Bitcoin. Finance Research Letters. In Press.

Baur, D.G., Lucey, B.M., 2010. Is gold a hedge or a haven? An analysis of stocks, bonds, and gold. Financial. Review. 45 (2), 217-229.

Beckmann, J., Berger, T., Czudaj, R., 2015. Does gold act as a hedge or a safe haven for stocks? A smooth transition approach. Economic Modelling, 48, 16-24.

Bentes S.R., 2016. Long memory volatility of gold price returns: How strong is the evidence from distinct economic cycles?, Physica A, 443, 149-160. 
Bouri, ,E, Shahzad, J., Roubaud, D., Kristoufek, L.; Lucey, B., 2020. Bitcoin, gold, and commodities as safe havens for stocks: New insight through wavelet analysis, The Quarterly Review of Economics and Finance, doi.org/10.1016/j.qref.2020.03.004.

Bouri, E., Hagfors, L.I., Molnar, P., 2017, a. On the hedge and haven properties of Bitcoin: is it more than a diversifier? Finance Research Letters, 20, 192-198.

Brière, M., Oosterlinck, K., Szafarz, A., 2015. Virtual currency, tangible return: portfolio diversification with bitcoin. Journal of Asset Management, 16 (6), 365-373.

Charfeddine L., Benlagha N., Maouchi Y., 2020. Investigating the dynamic relationship between cryptocurrencies and conventional assets: Implications for financial investors. Economic Modelling, 85, 198-217.

Corbet, S., Lucey, B., Urquhart, A., Yarovaya, L. (2019). Cryptocurrencies as a Financial Asset: A systematic analysis. International Review of Financial Analysis, 62, 182-199.

Corbet, S., Meegan, A., Larkin, C., Lucey, B., Yarovaya, L., 2018. Exploring the dynamic relationships between cryptocurrencies and other financial assets. Economics Letters. 165, 28-34.

Demir, E., Bilgin, M.H., Karabulut, G. Doker, A., 2020. The relationship between cryptocurrencies and COVID-19 pandemic. Eurasian Economic Review, 10, 349-360

Dyhrberg, A.H., 2016. Hedging capabilities of Bitcoin. Is it virtual gold? Finance Research Letters. 16, $139-144$.

Fakhfekh M, Jeribi A, Ghorbel A, Hachicha N. (2021). Hedging stock market prices with WTI, Gold, VIX, and cryptocurrencies: A comparison between DCC, ADCC, and GO-GARCH models. International Journal of Emerging Markets, in press. doi: 10.1108/IJOEM-03-2020-0264.

Fakhfekh, M., Jeribi, A. 2020. Volatility dynamics of cryptocurrencies returns Evidence from asymmetric and long memory GARCH models. Research in International Business and Finance. 54, 2-8.

Gajardo G., Kristjanpoller W., Minutolo, M. 2018. Does Bitcoin exhibit the same asymmetric multifractal crosscorrelations with crude oil, gold, and DJIA as the Euro, Great British Pound, and Yen? Chaos Solitons Fractals, 109, 195-205.

Ghorbel, A, Jeribi, A. (2021, a). Investigating the relationship between volatilities of cryptocurrencies and other financial assets. Decisions in Economics and Finance, in press. https://doi.org/10.1007/s10203-020-00312-9

Ghorbel A, Jeribi A. (2021,b) Contagion of COVID-19 pandemic between oil and financial assets: The evidence of multivariate Markov switching GARCH models. Journal of Investment Compliance, in press. doi: 10.1108/joic01-2021-0001.

Ghorbel, A., Jeribi, A. (2021, c). Volatility spillovers and contagion between energy sector and financial assets during COVID-19 crisis period. Eurasian Economic Review . https://doi.org/10.1007/s40822-021-00181-6

Guesmi, K., Saadi, S., Abid, I., Ftiti, Z., 2019. Portfolio diversification with virtual currency: evidence from bitcoin. International Review of Financial Analysis., 63, 431-437.

Jareno F., Gonzalez., M., Tolentino, M., Sierra, K., 2020. Bitcoin and gold price returns: A quantile regression and NARDL analysis. Resources Policy, 67, 101666.

Jeribi A, Jena SK, Lahiani A. (2021) Are Cryptocurrencies a Backstop for the Stock Market in a COVID-19-Led Financial Crisis? Evidence from the NARDL Approach. International Journal of Financial Studies. 9(3):33. https://doi.org/10.3390/ijfs9030033

Jeribi, A., Snene Manzli, Y. . (2021). Can cryptocurrencies be a haven during the novel COVID-19 pandemic? Evidence from the Tunisian Stock Market. Journal of Research in Emerging Markets, 3(1), 14-31. https://doi.org/10.30585/jrems.v3i1.555

Jeribi, A., Fakhfekh, M. (2021). Portfolio management and dependence structure between cryptocurrencies and traditional assets: evidence from FIEGARCH-EVT-Copula. Journal of Asset Management, 22, 224-239.

Jeribi, A., Ghorbel, A. (2021). Forecasting developed and BRICS stock markets with cryptocurrencies and gold: generalized orthogonal generalized autoregressive conditional heteroskedasticity and generalized autoregressive score analysis. International Journal of Emerging Markets, in press. https://doi.org/10.1108/ijoem-06-2020-0688

Kajtazi, A., Moro, A., 2018. The role of bitcoin in well-diversified portfolios: a comparative global study. International Review of Financial Analysis. 2011, 1-15,

Katsiampa, P., 2017. Volatility estimation for bitcoin: a comparison of GARCH models. Economics Letters. 158, 36. 
Klein, T., Pham Thu, H., Walther, T., 2018. Bitcoin is not the New Gold a comparison of volatility, correlation, and portfolio performance. International Review of Financial Analysis. 59, 105-116.

Kumah, S. P., Adjei Abbam, D., Armah, R., Appiah-Kubi, E. (2021). African financial markets in a storm: Cryptocurrency safe havens during the COVID-19 pandemic. Journal of Research in Emerging Markets, 3(2), 60-70.

Lahiani, A, Jeribi, A., Jlassi, N. (2021). Nonlinear tail dependence in cryptocurrency-stock market returns: The role of Bitcoin futures. Research in International Business and Finance, 56, 101351.

McCown, J.R. and Zimmerman, J.R. 2006. Is gold a zero-beta asset? Analysis of the investment potential of precious metals. Available from SSRN.

Nakamoto, S. (2008). Bitcoin: A Peer-to-Peer Electronic Cash System.

Selmi, R., Mensi, W., Hammoudeh, S., Bouoiyour, J., 2018. Is Bitcoin a hedge, a safe haven or a diversifier for oil price movements? A comparison with gold. Energy Economics, 74, 787-801.

Symitsi, E., and Chalvatzis, K. J., 2019. The economic value of Bitcoin: A portfolio analysis of currencies, gold, oil and stocks. Research in International Business and Finance, 48. 97-110.

Tiwari A-K. Raheem I-D, Kang S-H., 2019. Time-varying dynamic conditional correlation between stock and cryptocurrency markets using the copula-ADCC-EGARCH model. Physica A: 535, 1-9.

(C) 2020 by the authors. This article is an open-access article distributed under the terms and conditions of the Creative Commons Attribution (CC BY) license (http://creativecommons.org/licenses/by/4.0/). 